\title{
Nuevos datos acerca de los repertorios teatrales en el primer catálogo de El peregrino en su patria ${ }^{1}$
}

\author{
Daniel Fernández Rodríguez \\ Universitat Autònoma de Barcelona \\ daniel.fernandez@uab.es
}

Recepción: 22/02/2014, Aceptación: 18/04/2014, Publicación: 17/12/2014

\section{Resumen}

En este artículo se muestra cómo los títulos que contienen los repertorios de los autores de comedias presentes en El peregrino en su patria de 1604 están dispuestos según un orden cronológico, aunque con algunos matices y no pocas excepciones. Además, se amplían los repertorios descubiertos por Thornton Wilder y se afina la fecha de composición de varias obras, prestando especial atención a textos que se han perdido, como La perdición de España, La gobernadora, La gran pintora, La bella gitana o La toma de Álora. Finalmente, el presente artículo pretende mostrar de un modo práctico cómo una base de datos digital como el Diccionario biográfico de actores del teatro clásico español (DiCAT) puede resultar de gran ayuda a la hora de resolver algunos de los problemas clásicos de la filología en general y del teatro del Siglo de Oro en particular.

\section{Palabras clave}

Lope de Vega; El peregrino en su patria; catálogo; repertorios teatrales; cronología; autores de comedias; DicaT; Thornton Wilder

\section{Abstract}

New information on the theatrical repertoire of the firts catalogue of $\mathrm{El}$ peregrino en su patria This paper shows that the plays contained in the repertoire of the autores de comedias

1. El presente trabajo se beneficia de mi participación en los proyectos TC/12 «Patrimonio teatral clásico español. Textos e instrumentos de investigación» TECE-TEI Consolider CSD200900033 (Ministerio de Ciencia e Innovación) y «Edición y estudio de treinta y seis comedias de Lope de Vega» FFI2012-35950 (Ministerio de Economía y Competitividad). 
which appear in El peregrino en su patria (1604) are organised chronologically, although there are some nuances and exceptions. The article also expands the repertoire discovered by Thornton Wilder and sets the date of composition for some plays, paying special attention to lost texts such as La perdición de España, La gobernadora, La gran pintora, La bella gitana or La toma de Álora. Finally, this paper attempts to show in a practical way that a database such as the Diccionario biográfico de actores del teatro clásico español (DiCAT) can be extremely helpful when it comes to dealing with some of the philology's classical problems in general and those of the theatre of the Golden Age in particular.

\section{Keywords}

Lope de Vega; El peregrino en su patria; catalogue; theatrical repertoire; chronology; autores de comedias; DICAT; Thornton Wilder

La aparición en 1603 del volumen titulado Seis comedias de Lope de Vega (Lisboa, Pedro Crasbeeck) sirvió de acicate para que el Fénix emprendiera la publicación del catálogo de El peregrino en su patria, que supone un primer intento de "proporcionar el canon de sus obras teatrales auténticas» (Giuliani 2004: 132). El impreso lisboeta se valió de la fama de Lope como reclamo publicitario, cuando en realidad contenía una única comedia lopesca, $E l$ perseguido: ${ }^{2}$

Mas ¿quién teme tales enemigos? Ya para mí lo son los que con mi nombre imprimen ajenas obras. Ahora han salido algunas comedias que, impresas en Castilla, dicen que en Lisboa, y así quiero advertir a los que leen mis escritos con afición (que algunos hay, si no en mi patria, en Italia y Francia y en las Indias, donde no se atrevió a pasar la envidia) que no crean que aquéllas son mis comedias, aunque tengan mi nombre, y para que las conozcan me ha parecido acertado poner aquí los suyos [...] (El peregrino en su patria, p. 57).

En un artículo clásico, Thornton Wilder $(1952)^{3}$ demostró que muchos de los títulos incluidos en el catálogo de El peregrino en su patria, publicado en

2. Sobre el volumen Seis comedias de Lope de Vega véase el reciente estudio de Iglesias Feijoo (2013).

3. Por razones de accesibilidad he consultado la reciente traducción española de Guillem Usandizaga — por la que cito siempre en este artículo_, reseñada en la bibliografía (Wilder 2004). 
1604 y con fecha de aprobación de noviembre de 1603, estaban agrupados en función del autor de comedias al que fueron vendidos los textos. Parece que solo en dos ocasiones apuntó Wilder la posibilidad de que algunas de las obras pudieran seguir un orden cronológico. Así, al estudiar la fecha de composición de las comedias incluidas en la lista de Baltasar de Pinedo, advirtió una "sequence of many of the Peregrino numbers» (1953: 22). ${ }^{4}$ Wilder parece referirse asimismo a esta cuestión cuando, a raíz de la edad de uno de los nińos que figuraba en el reparto de la compañía de Pinedo, observa que la comedia La fuerza lastimosa «is among the earliest that Lope wrote for Pinedo - a supposition confirmed by the position of the title in the Peregrino list" (Wilder 1953: 21). No termina de quedar claro si con «the position of the title in the Peregrino list» se refiere Wilder a que La fuerza lastimosa figura dentro de la lista de obras estrenadas por Pinedo o, de modo más específico, a que aparece en las primeras posiciones - concretamente en el segundo lugar - de dicha lista, en cuyo caso se estaría apuntando de nuevo la posibilidad de que las comedias estrenadas por Pinedo hubieran sido ordenadas mediante un criterio cronológico por parte de Lope.

En este artículo pretendo demostrar que los títulos que contienen los repertorios de los distintos autores de comedias presentes en El peregrino en su patria están dispuestos según un orden cronológico, aunque con algunos matices y no pocas excepciones. Por otro lado, trataré de ampliar los repertorios descubiertos por Wilder y de fijar la fecha de composición de varias de sus obras, así como de aportar nuevos datos acerca de algunos de los títulos que se han perdido. Para todo ello me ha sido de una enorme utilidad la base de datos del Diccionario biográfico de actores del teatro clásico español (DicaT), dirigido por Teresa Ferrer Valls (2008). En este sentido, el presente artículo pretende asimismo mostrar de un modo práctico cómo una base de datos digital puede ser de gran ayuda para abordar algunos de los problemas clásicos de la filología en general y del teatro del Siglo de Oro en particular.

En los repertorios del Peregrino que presentaré a continuación, señalo con el signo «+» aquellas obras sobre las que existe documentación que las relacione con el autor de comedias en cuyo repertorio se incluyen. ${ }^{5}$ Marco en cambio con un asterisco aquellas comedias que no se han conservado. ${ }^{6} \mathrm{Si}$ no se indica lo contrario, las fechas de composición se corresponden con las que ofrecen Morley y Bruerton (1968). Por lo demás, puede consultarse una edición facsímil del catálogo de El peregrino en su patria en el apéndice de Tubau (2004), que incluye un útil índice de títulos para su rápida localización.

4. Wilder numeró las comedias en función de su posición en el Peregrino.

5. Todos los datos se pueden recuperar mediante una sencilla búsqueda en Dicat.

6. El Dicat aporta datos acerca de posibles representaciones de algunas de las comedias perdidas, pero solo se han traído a colación aquellos que revisten interés para los objetivos de este artículo. 


\section{Antonio Granados}

La lista de comedias estrenadas por Antonio Granados («gallardo galán, gentil hombre y de la tierra del Peregrino») ${ }^{7}$ está formada por obras compuestas en una fecha muy próxima a la aprobación de El peregrino en su patria, ya que las más antiguas fueron escritas apenas un año antes de noviembre de 1603:

+ El cuerdo loco

+ Los esclavos libres

+ El principe despeñado

+ El Arenal de Sevilla

+ La gallarda toledana

+ La corona merecida

+ Pedro Carbonero ${ }^{12}$
11 de noviembre de 1602 (autógrafo fechado) $^{8}$

Finales de $1602^{9}$

27 de noviembre de 1602 (autógrafo fechado)

29 de enero - 17 de mayo de $1603^{10}$

Finales de enero - principios de noviembre de 1603 $1603^{11}$ (autógrafo)

26 de agosto de 1603 (autógrafo fechado)

El orden cronológico, siquiera aproximado, parece evidente. No es de extrańar: a fin de cuentas, Lope debió de redactar el catálogo del Peregrino en el otońo de 1603, por lo que la más antigua de estas comedias apenas llevaría un año sobre las tablas, de modo que el Fénix tendría muy presente aún el orden en que las fue componiendo.

Una consulta en el DicaT ofrece un dato muy interesante: el 12 de diciembre de 1604 el autor de comedias Gaspar de Porres representó en Salamanca una obra titulada El Arenal de Sevilla. Este hecho podría ser un indicio de que Lope no le vendió el autógrafo a Granados, sino a Porres, y que por tanto Granados se hizo con una copia posterior del texto: «A base de esta noticia se puede afirmar que Lope escribió El arenal de Sevilla para la compañía de Porras» (Haley 1971: 261). A raíz de las estancias del Fénix en Sevilla a lo largo de $1603^{13}$ y de varias funciones de la compañía de Porres en la capital hispalense en junio de ese mismo año, Haley (1971: 261) plantea la siguiente posibilidad: «¿Escribiría Lope esta comedia

7. Tal y como le describe Lope en El peregrino en su patria, p. 482.

8. Para los autógrafos de Lope remito siempre a Presotto (2000).

9. Los esclavos libres aparece en un documento firmado por Granados el 18 de enero de 1603 — que comentaremos a continuación - en el que figura como "comedia nueva» junto a El cuerdo loco y El príncipe despeñado, compuestas en noviembre de 1602. Tal y como ya sugirieron Juana de José Prades y Alicia López (2000: 137), este hecho implica que tuvo que ser escrita en una fecha muy cercana, a finales de ese mismo año. Por su parte, Morley y Bruerton (1968: 50) le habían asignado la fecha 1599-1603. Lope recuerda el estreno de Los esclavos libres por la compañía de Granados en El peregrino en su patria (p. 482) y en en la Parte XIII: «Representola Granados» (Los esclavos libres, p. 397b).

10. Véanse los múltiples datos reunidos por Cornejo (2012: 461-466).

11. Al autógrafo de La corona merecida le faltan las últimas páginas. La fecha de 1603 nos ha llegado gracias a un índice manuscrito preparado por Agustín Durán (Menéndez Pelayo 1898: cxxiv).

12. Con este nombre figura también en la Parte $X I V$, mientras que en el autógrafo se titula $E l$ cordobés valeroso, Pedro Carbonero.

13. Sobre este aspecto véase Cornejo (2003 y 2012: 466-468). 
en Sevilla para que la compañía de Porras pudiera estrenar una comedia de asunto sevillano durante su estancia en aquella ciudad en junio de 1603?». Sin embargo, pese a la temprana fecha de representación por parte de Porres, es mucho más probable que fuera Granados quien adquiriera el autógrafo de Lope, habida cuenta de que El Arenal de Sevilla figura en la lista de obras que le vendió Lope y de que Granados, como veremos a continuación, afirma haber pagado 500 reales por ella, esto es, el precio de un autógrafo (Díez Borque 1978: 103-104).

Por lo que respecta a La gallarda toledana, ${ }^{14}$ la crítica ha situado su terminus a quo en 1601, fecha que nos ofrece el propio texto, pues son varias las alusiones al traslado de la corte de Madrid a Valladolid ("corte del Tercer Filipo», v. 820), que fue capital del reino entre 1601 y 1606 . De nuevo, una búsqueda en Dicat arroja datos muy interesantes. En primer lugar, tenemos constancia de que el 18 de enero de 1603, los autores de comedias Antonio Granados y Pedro de Valdés unen sus compañías teatrales para un proyecto común de representación por un período de dos años. ${ }^{15}$ Antonio Granados se compromete a aportar a la compañía todas aquellas «comedias nuevas» (es decir, los autógrafos de las mismas) de que disponga; en el momento de firmar el acuerdo, Granados aporta cinco comedias «nuevas, e que no se han representado, ni persona alguna tiene de ellas traslado", entre ellas tres de Lope: El cuerdo loco, Los esclavos libres y El príncipe despeñado. ${ }^{16}$ Granados se compromete asimismo a "poner y meter en esta compañía todas las comedias que hasta hoy dicho día ha fecho y representado con su compañía». Un documento fechado en 1606 deja constancia de que Granados regaló a los autores Juan de Arteaga y Juan Osorio cuatro comedias, dos de ellas de Lope (El mármol de Felisardo y Los esclavos libres), ${ }^{17}$ a condición de que no representasen jamás una serie de obras —entre las que figuraba La gallarda toledana - por las que Granados afirmaba haber pagado los 500 reales que costaba un autógrafo, cantidad que tendría que cobrar en caso de que alguna compañía decidiera llevarlas a escena. De las doce obras lopescas de atribución segura de las que disponía Granados en 1606 según la citada documentación, ${ }^{18}$ solo tres son anteriores a 1603 con total seguridad: Los esclavos libres (finales de 1602), El

14. Lope recuerda el estreno de La gallarda toledana por parte de Granados en la edición princeps de la obra («Representola Granados»). Las citas provienen siempre de la edición crítica que estoy preparando.

15. Presotto (1997: 154) comenta varios aspectos de este contrato, que transcribió San Román (1935: 71-76). En las citas del mismo, correspondientes a las páginas 75 y 72, modernizo la ortografía.

16. Las otras dos comedias no se han conservado: se trata de Roldán casado, de Alonso Remón, y El español de más fuerzas, de Damián Salustio del Poyo.

17. Los otros dos títulos, El santo loco del desierto y El prado de Valladolid, son de autor desconocido y no se han conservado.

18. Dejo de lado Julián Romero y San Ángelo carmelita, de autoría dudosa (Morley y Bruerton 1968). Completan la lista tres comedias más, de autor desconocido: La torre de Sevilla, La fuerza de naturaleza y reyes de un ju[...] —cuyo título completo es ilegible — y Luis y Alejandro (DicaT). 
príncipe despeñado ${ }^{19}$ y El cuerdo loco (ambas con autógrafos fechados en noviembre de 1602). Se trata efectivamente de los tres títulos que se mencionan en el documento de 1603. Dejando de lado por ahora La gallarda toledana, sabemos que todas las comedias de Lope de atribución y fecha de redacción seguras que no aparecían en dicho documento y que en 1606 Granados prohibía representar, fueron escritas entre 1603 y 1604 . Por un lado, contamos con varios manuscritos autógrafos fechados, como Pedro Carbonero, La corona merecida (ambas de 1603), La prueba de los amigos, La desdichada Estefanía ${ }^{20}$ y Carlos V en Francia (las tres de 1604), y, por otro, con comedias que han podido ser fechadas a partir de distintos datos, como El Arenal de Sevilla (1603) o El marqués de Santa Cruz (cuyo terminus a quo es 1604). ${ }^{21}$ Todo indica que, en efecto, Granados aportó a la compañía todas las comedias nuevas de Lope que estaban en su poder en enero de 1603, momento en el que aún no disponía de La gallarda toledana, por lo que hay que suponer que Lope aún no la había escrito.

Se podría aducir no obstante que la obra pudo haber formado parte de aquellas «comedias viejas» que Granados «hasta hoy dicho día [18 de enero de 1603] ha fecho y representado con su compañía», y por tanto adelantar su posible fecha de redacción hasta 1601 o 1602 . Esto me parece muy improbable por varias razones. Para empezar, las primeras noticias que tenemos acerca de la compañía de Granados, cuya «actividad profesional [...] como autor de comedias está bien documentada durante un período de más de treinta años» (García Reidy 2013: 117), se sitúan en la primavera de 1602. Por lo tanto, una fecha anterior a la primavera de 1602 es una hipótesis que carece de apoyo documental. Pero aun suponiendo que Granados hubiera formado su compañía antes de esa fecha, resultaría muy extraño que, si ya había venido representando La gallarda toledana durante uno o dos años antes que Los esclavos libres — comedia que en enero de 1603 aún no había sido estrenada - , decidiera sin embargo desprenderse en 1606 de esta obra y quedarse con aquella, más antigua y, por lo tanto, con menor capacidad para entretener al público. Una fecha de redacción situada entre la primavera y el verano de 1602 implicaría que Lope vendió La gallarda toledana a Granados en cuanto este formó su compañía, lo que no dejaría de ser sorprendente teniendo en cuenta que por aquel entonces cualquier compañía de primera fila buscaba representar obras del Fénix; más probable es que Lope, en vista del éxito que debieron de alcanzar las primeras representaciones de Granados, decidiera, «al poco de que Granados formara su compañía en 1602» (García Reidy 2013: 117) —es decir, a

19. El príncipe despeñado figura con el título El principe desterrado, pero se trata seguramente de la misma comedia.

20. Con este mismo título se publicó en la Parte XII; en el autógrafo figura como Estefanía la desdichada.

21. Se trata con toda probabilidad de La nueva victoria del marqués de Santa Cruz, fechada por Morley y Bruerton (1968: 85): «La batalla que canta ocurrió en 1604 [...] y, como no fue importante, se escribió la comedia probablemente poco después». 
finales de ese año- venderle El cuerdo loco, Los esclavos libres y El principe despeñado. Nótese además que las otras once comedias lopescas de atribución segura que poseyó Granados fueron escritas entre finales de 1602 y 1604, ${ }^{22}$ lo que hace aún más improbable adelantar el terminus a quo. Por último, la fecha que proponemos viene avalada por la posición de La gallarda toledana dentro de la lista de obras estrenadas por Granados, que como iremos viendo es una de las que parece respetar la cronología de un modo más estricto. Este hecho se explica probablemente porque la de Granados es la lista formada por obras más cercanas al momento de escritura del Peregrino. Así pues, lo más probable es que La gallarda toledana fuera compuesta entre finales de enero y principios de noviembre de 1603.

Conviene detenernos ahora en tres comedias que figuran asimismo en el documento de 1606 y que plantean varios interrogantes: El mármol de Felisardo, El rey don Sebastián y García de Paredes. El mármol de Felisardo fue fechada por Morley y Bruerton (1968: 250) entre 1594 y 1598, aunque admiten que «es difícil fechar la comedia por el verso", por lo que hay que tomar este dato con ciertas reservas. Si la hipótesis de Morley y Bruerton es correcta, la ausencia de El mármol de Felisardo en el documento de enero de 1603 y su presencia en la escritura de 1606 como una de las comedias regaladas, podrían ser un indicio de que Granados adquirió una copia de la obra cuando esta ya había sido representada por otros autores de comedias, pues hay constancia de una puesta en escena en Salamanca el diez de septiembre de 1604, muy probablemente a cargo de los autores Baltasar de Pinedo o Nicolás de los Ríos (Dicat). Se entendería así que en 1606 la obra ya no le proporcionara muchos réditos económicos, y que por tanto pudiera fácilmente regalarla a Arteaga y Osorio. En el catálogo del Peregrino, El mármol de Felisardo figura justo a continuación de Pedro Carbonero. El hecho de que aparezca junto a las comedias estrenadas por Granados podría llevarnos a incluirla entre las de su repertorio, pero la fecha propuesta por Morley y Bruerton (1594-1598) no lo permite por dos motivos: por un lado, las primeras noticias que se conservan de la compañía de Granados datan de la primavera de 1602; por otro, la comedia no respetaría el orden cronológico de la lista de Granados, constituyendo un caso absolutamente excepcional en el catálogo del Peregrino: como iremos viendo, Lope sitúa las comedias más antiguas al inicio de cada lista, especialmente cuando fueron compuestas varios años antes que el resto de obras, y las más recientes al final. De este modo, solo en el caso de que se pudiera retrasar su fecha de composición hasta 1603 podríamos plantearnos la posibilidad de que fuera estrenada por Granados. Más adelante volveremos sobre la cuestión de El mármol de Felisardo.

El rey don Sebastián y García de Paredes figuran entre las comedias que en 1606 Granados prohibía representar y por las que afirmaba haber pagado los 500

22. Salvo El mármol de Felisardo, cuya temprana fecha de redacción (1594-1598 según Morley y Bruerton) parece ser un indicio de que, como veremos a continuación, Granados se hizo muy probablemente con una copia posterior de la obra. 
reales que costaba un autógrafo. ${ }^{23}$ La comedia de Lope El bautismo del principe de Marruecos, escrita entre la segunda mitad de 1601 y $1603,{ }^{24}$ lleva por título $E l$ rey don Sebastián en varios de sus testimonios (Pontón 2012: 823-824), de modo que es posible que se trate del mismo texto que poseyó Granados. Existen sin embargo otras obras con títulos muy semejantes, por lo que conviene extremar la cautela. Baste recordar una Gran comedia del rey don Sebastián, compuesta por Francisco de Villegas, la Comedia famosa del rey don Sebastián, escrita por Luis Vélez de Guevara poco antes de 1607 y estrenada por Alonso de Riquelme (Herzog 1972: 22-24), y El rey don Sebastián y portugués más heroico, de Juan Bautista de Villegas. ${ }^{25}$ Por otro lado, algunos datos apuntan a que quizás fue Antonio de Villegas el encargado de llevar a las tablas El bautismo del príncipe de Marruecos (Pontón 2012: 812). El hecho de que esta obra figure en el catálogo del Peregrino — con el título de El príncipe de Marruecos - pero no en la lista correspondiente a Granados podría ser un indicio de que Lope vendió el autógrafo a otro autor de comedias; sin embargo, en el catálogo hay más de una obra que no aparece en la lista del autor encargado de estrenarla, como El primer rey de Castilla, El sol parado o El perseguido. ${ }^{26}$ No es del todo seguro, en fin, que la obra estrenada por Granados se debiera a la pluma del Fénix.

Respecto a García de Paredes, los datos de que disponemos nos hacen suponer que no se trata de la comedia de Lope La contienda de García de Paredes y el capitán Juan de Urbina. En primer lugar, la copia Gálvez de La contienda aporta la fecha de 15 de febrero de 1600 (Iriso 1997: 105): como ya se ha comentado,

23. Hay constancia de dos puestas en escena de una comedia titulada El rey don Sebastián los días 7 y 9 de diciembre de 1606, probablemente a cargo de la compañía de Juan de Arteaga (DiCAT): si fue en efecto Arteaga quien llevó a cabo dichas representaciones, habría incumplido el acuerdo con Granados, salvo que la escritura de 1606 hubiera sido firmada en las últimas semanas de diciembre. 24. Tal y como ha demostrado recientemente Gonzalo Pontón: «Cuando, ante la inminente conversión del Jeque, uno de los personajes cristianos, el corregidor de Andújar, celebra las "cosas estrañas" ['prodigiosas'] que "se ven / en tiempos del gran Filipo" (vv. 2235-2236), hace hincapié en las numerosas canonizaciones de nuevos santos hispánicos, entre los que tiene a bien destacar los siguientes: "San Julián y San Segundo / tienen gran veneración, / Raimundo y Jacinto son, / con Diego, soles del mundo" (vv. 2247-2250) [...]. Todos ellos, en efecto, son santos canonizados en el último decenio de vida del Rey Prudente, con una sola excepción: "Raimundo", que no puede ser otro que el de Peńafort, elevado a los altares en Roma el 29 de abril de 1601. El pequeño desliz de Lope (dar por santo a quien aún no lo era en tiempos de Felipe II) deja traslucir el presente de la escritura y apunta a la segunda mitad de 1601 como la fecha más temprana de composición, a notable distancia del bautismo y ya en los primeros ańos de Felipe III [...]. Si la damos por compuesta en 1601-1603 (y más probablemente 1602-1603), la comedia se ve despojada de su valor noticioso, o por lo menos de su carácter urgente, y se aprecian mejor algunos de sus matices [...]» (Pontón 2012: 800-801).

25. Para más detalles y bilbiografía, véanse Pontón (2012: 812-813) y el Dicat.

26. Lope vendió el autógrafo de El primer rey de Castilla a Luis de Vergara, pero el título no figura en su lista de comedias, sino bastante antes. Otro tanto ocurre con $E l$ sol parado, estrenada por Nicolás de los Ríos - Lope recuerda el estreno de ambas obras por parte de dichos autores al frente de la edición de cada una de ellas (Dicat). En cuanto a El perseguido, la comedia aparece en la lista de Ríos, cuando en realidad fue Alonso de Cisneros el encargado de llevarla a las tablas (Wilder 2004: 190). 
las primeras noticias de la compañía de Granados datan de 1602, y las comedias lopescas que estrenó no son anteriores a noviembre de ese mismo año. Además, en el catálogo del Peregrino el título El capitán Juan de Urbina no aparece junto a las obras estrenadas por Granados. Puesto que Granados afirma haber pagado 500 reales por ella, lo más probable es que García de Paredes fuera obra de otro dramaturgo. Al fin y al cabo, no son pocos los escritores del Siglo de Oro que se inspiraron en el Sansón de Extremadura, como se llamaba en la época al célebre militar Diego García de Paredes, natural de Trujillo. ${ }^{27}$

\section{Luis de Vergara}

Según la información que hemos podido recabar, Lope redactó la lista de comedias estrenadas por Luis de Vergara ("general en todo género de representaciones») ${ }^{28}$ siguiendo de nuevo un orden cronológico:

+ El favor agradecido

+ El caballero del milagro

+ El leal criado

La reina loca*

+ El Argel fingido

+ El esclavo de Roma

+ El bosque amoroso*

+ Los locos por el cielo La perdición de España*

+ Angélica en el Catay La cadena*

+ La prisión sin culpa
19 de diciembre de 1593 (autógrafo fechado) 30 de noviembre de 1593 (copia Gálvez) ${ }^{29}$ 24 de junio de 1594 (autógrafo perdido) $^{30}$

1596-1603

1598-1603

1599-1603

$1599-1600^{31}$

27. Luis de Belmonte Bermúdez, por ejemplo, compuso una comedia titulada Darles con la entretenida — transmitida asimismo con el título Diego García de Paredes - que fue identificada por Rennert (1906-1907: 341) con una obra, titulada García de Paredes, representada por Granados en 1626 (Dicat). Tampoco sabemos si la comedia Los hechos de García de Paredes, llevada a las tablas el 12 de diciembre de 1605, probablemente a cargo de la compañía de Nicolás de los Ríos (Dicat), se corresponde con la obra de Lope. Un último dato de interés, pero que no nos permite esclarecer el asunto, es que el 4 de diciembre de 1611 el actor Pedro de Vitoria requirió a un notario para que levantara acta de que Granados había representado en Zaragoza una comedia llamada La segunda parte de García de Paredes. Según San Vicente (1972: 299), «la finalidad del testimonio auténtico requerido por Vitoria puede ser de tipo judicial, si la obra representada pertenecía al repertorio de otro "autor de comedias" que no fuese Granados» (Dicat). Sobre la figura de Diego García de Paredes en la literatura española del siglo XVI, véase Sánchez Jiménez (2006).

28. El peregrino en su patria, p. 482.

29. Las fechas de los manuscritos copiados por Ignacio Gálvez proceden siempre de Iriso (1997). 30. La fecha ha sido transmitida por la copia realizada en 1781 por Sanz de Pliegos (Cotarelo 1930: XII).

31. Sigo la datación propuesta por Rafael Ramos (2009b: 873): «Morley y Bruerton fijaron su redacción entre 1599 y 1603 . Quizá podríamos precisar el momento de su composición más cerca de la primera fecha que de la segunda, pues se menciona Madrid como sede de la Corte (dejó de serlo 
+ La bárbara del cielo*

+ El primer Fajardo
Antes de 1599

$1600-1603^{32}$

Es obvio que Lope anotó en primer lugar un grupo de comedias antiguas (El favor agradecido, El caballero del milagro y El leal criado), compuestas nueve o diez años antes de redactar el catálogo del Peregrino, y, a continuación, escribió el título de las más recientes, todas ellas pertenecientes a los últimos cuatro o cinco años. Con todo, la escasez de datos concretos nos impide valorar con exactitud el grado de precisión cronológica de Lope.

La base de datos del DicAT resulta de gran ayuda para poder resolver algunas de las incógnitas que plantean los títulos que se han perdido. En primer lugar permite fijar el terminus ad quem de La bárbara del cielo y corroborar que fue Vergara quien la estrenó, ya que la obra figura en un documento fechado el 13 de enero de 1599, según el cual el autor Mateo de Salcedo y los actores Lope de Avendańo y Jerónima Salcedo se comprometen a no representar varias obras de Vergara, entre ellas La bárbara del cielo. ${ }^{33}$ Tenía razón Wilder (1952), pues, al incluirla en el repertorio de Luis de Vergara. ${ }^{34}$

Por otro lado, sabemos que el día 1 de junio de 1605 se representó en Salamanca El bosque de amor, título que se corresponde sin duda alguna con la comedia que figura en la lista de Vergara como El bosque amoroso. ${ }^{35}$ Las razones para llevar a cabo esta identificación no tienen que ver solamente con la semejanza onomástica, sino, sobre todo, con el hecho de que el autor de comedias que la

en $1601[\ldots])$ y se nos informa de que el archiduque Alberto de Austria está preparando su traslado a Namur, en Flandes [...], acontecimiento que se puede referir tanto a su primer viaje, tras su designación como gobernador de los Países Bajos (en 1596), como al segundo, tras su matrimonio con Isabel Clara Eugenia de Austria, hija de Felipe II (en 1599), aunque este último es menos probable, pues la pareja partió de Barcelona, no de Madrid, tras su boda en Valencia. Como el primer viaje pronto debió quedar eclipsado por el segundo, el periodo 1599-1600 parece imponerse como el más probable para fechar la comedia».

32. Para la datación de esta pieza adopto el razonamiento de Jorge García López (2008: 969): «El primer Fajardo es la misma comedia, y no hay por qué dudarlo, que Lope anuncia como Los Fajardos en la famosa lista de El Peregrino en su patria (1604); de hecho, el título Los Fajardos parece cuadrar mejor con las hazañas de varios Fajardos que Lope parece haber fundido en su héroe dramático. A pesar de este dato, concluyente ya de por sí, Morley y Bruerton sitúan su composición en fecha bastante más tardía, y dan como la más probable alguna comprendida entre los años 1610 y 1612, si bien no descartan retrotraerla hasta 1600. [...] Sin embargo, El primer Fajardo es, desde el punto de vista estético y estructural, una comedia muy inferior a las de esa época».

33. Alejandro García Reidy (2007: 465) ya había llamado la atención sobre este hecho.

34. En la colección Gondomar, gestada "hacia la mitad de los años 90 del siglo XVI» (Arata 2002: 154), se encuentra una obra titulada Vida y martirio de Santa Bárbara, pero su estilo no se corresponde con el de Lope, según los datos ofrecidos por Reyes Peña (2003: 749-752).

35. La representación de El bosque de amor por parte de Vergara había sido apuntada por Agustín de la Granja (2000: 65 n. 118), quien ya la había identificado con El bosque amoroso del Peregrino, obra que según el citado investigador Lope vertería a lo divino en el auto sacramental titulado asimismo El bosque de amor (Granja 2000: 63-65). 
llevó a las tablas fue con toda probabilidad el propio Luis de Vergara — tal y como se sugiere en el DicAT- ya que por aquellas fechas están atestiguadas varias representaciones suyas en Salamanca, concretamente los días 29, 30 y 31 de mayo. Tenemos noticia además de que el 3 y el 4 de junio se representó en Salamanca la obra El desposorio encubierto. Aunque no figure su nombre en el testimonio conservado que da fe de la puesta en escena, el autor que estrenó El desposorio encubierto no fue otro que Vergara, ${ }^{36}$ lo cual constituye otra evidencia de que fue él quien representó El bosque de amor. Todas las piezas encajan: una obra desconocida, pero que muy probablemente fue estrenada por Vergara (debido a su aparición en la lista correspondiente del Peregrino), aparece citada — con un título muy similaren un documento que da cuenta de su puesta en escena en la fecha y en el lugar en los que se encontraba representando su compañía.

El 2 de junio de 1605, al día siguiente de la representación de El bosque de amor, el público de Salamanca tuvo ocasión de ver una obra titulada El último godo o La destrucción de España. Este hecho constituye un indicio más de que el estreno de El bosque de amor corrió a cargo de Vergara. El último godo o La destrucción de España es sin duda alguna la misma obra que conocemos con el título El postrer godo de España, ${ }^{37}$ comedia que, como es sabido, fue estrenada por Vergara. El 29 de febrero de 1616 Juan Fernández, vecino de Madrid, vendió a Francisco de Ávila, mercader de lienzos, «doce comedias compuestas por Lope de Vega Carpio, las cuales se han ya representado» al precio de 72 reales. ${ }^{38}$ Estas comedias, entre las que se encontraba El postrer godo de España, fueron «sacadas y copiadas de sus originales, que estaban en poder de María de la $\mathrm{O}$, viuda, mujer que fue de Luis de Vergara, autor de comedias». Ello dio pie al famoso pleito entre Lope de Vega y Francisco de Ávila, que Lope terminó perdiendo, y que se saldó con la publicación de la Séptima y Octava parte de comedias, en las que figuran casi todas las obras de Lope estrenadas por Vergara que Juan Fernández vendió a Francisco de Ávila. ${ }^{39}$

El postrer godo de España se inspira en el episodio de la violación de la Cava a manos del rey don Rodrigo, la derrota del último rey godo, la invasión musulmana de la Península y el inicio de la Reconquista por parte de don Pelayo. Según Morley y Bruerton (1968: 265), fue escrita entre 1599 y 1603, fecha que acepta su editor más reciente, Jorge García López (2009: 725). Lope la cita con este mismo título, El postrer godo de España, en la lista del Peregrino de 1618, y como tal se publicó en la Parte VIII. Este título no aparece en cambio en la lista de 1604. Con todo, resulta evidente que El último godo o La destrucción de España y El postrer godo de España son en realidad la misma obra. La comedia debió de circular en-

36. Lo recuerda el propio Lope: «Representola Vergara» (El desposorio encubierto, p. 507b).

37. Tal y como ha señalado Urzáiz Tortajada (2002: II, 676).

38. Cito por Ramos (2009a: 12).

39. Para más detalles, remito a Di Pastena (2008: 9-15) y Ramos (2009a: 9-22). 
seguida con varios títulos, como era habitual. El último godo, título casi idéntico, contaba además con circunstancias que le eran propicias, como los últimos versos de la obra: "Aquí discreto senado / se acaba El último godo». ${ }^{40}$ De hecho, el texto transmitido en la extravagante Parte $X X V$, que proviene de una compañía teatral, ${ }^{41}$ lleva por título Tragicomedia el último godo (García López 2009: 749).

Pues bien, si echamos la vista atrás al repertorio de Vergara, observamos que una de las comedias desaparecidas lleva por título La perdición de España. Sin duda, resulta tentador identificar esta obra con El postrer godo de España, conocida también como El último godo o La destrucción de España. Del mismo modo que en el caso de El bosque de amor, esta identificación vendría avalada no solo por la semejanza onomástica, sino porque La perdición de España aparece en la lista de comedias estrenadas por Vergara, que fue el encargado de representar $E l$ último godo o La destrucción de España. ${ }^{42}$

Sin embargo, en su Índice de todas las comedias impresas hasta el año de 1716, Juan Isidro Fajardo cita y atribuye al Fénix una obra titulada "Pérdida de España y descendencia de los Ceballos, de Lope» (f. 41). ${ }^{43}$ Este hecho, tal y como apuntó Menéndez Pelayo (1901: 255), demuestra que la comedia «existía aún a principios del siglo XviII». Lo más probable, por tanto, es que dicha obra sea la misma que cita Lope con el título La perdición de España. Con todo, carecemos de datos suficientes como para poder descartar con total seguridad que, por los motivos anteriormente expuestos, La perdición de España y El último godo o La destrucción de España fueran en realidad la misma obra. ${ }^{44}$

40. Lope de Vega, El postrer godo de España, vv. 2815-2816.

41. "Nuestra conclusión es que la Parte $X X V$ no contiene una redacción diferente de El postrer godo de la que representan los textos de la Octava parte de 1617; se trata, simplemente, de un texto salido de las compañías de representantes» (García López 2009: 741).

42. No sería un obstáculo para llevar a cabo dicha identificación el hecho de que el título $L a$ perdición de España aparezca de nuevo en el catálogo del Peregrino de 1618, en el que Lope añade asimismo el de El postrer godo de España. Hay varios casos más de comedias que figuran con diferentes nombres en la lista de 1618, hecho que se explica fácilmente porque los títulos, tan distintos entre sí, debían de ser irreconocibles incluso para el propio Lope, dejando de lado su posible afán por engrosar el catálogo de su producción dramática. A modo de ejemplo, refiero a continuación cinco casos de comedias que aparecen citadas con dos títulos distintos en la lista de 1618 (el primero de ellos se encuentra tanto en el catálogo de 1604 como en el de 1618, mientras que el título entre paréntesis figura solo en este último): El cuerdo loco (El veneno saludable), Los Horacios (El honrado hermano), El primero Médicis (La quinta de Florencia), Abindarráez y Narváez (El remedio en la desdicha), Nerón cruel (Roma abrasada). Estos dobletes no son sino peccata minuta, sobre todo si tenemos en cuenta otros despistes, mayúsculos, de Lope, que en la lista de 1618 repite varios títulos sin la más ligera variación: El africano cruel, Los amantes sin amor, El amigo por fuerza, El amor desatinado, El caballero de Illescas, etc.

43. Se trata del manuscrito 14.706 de la Biblioteca Nacional de Madrid.

44. Según se puede leer en el Dicat, en octubre del año 1622 la compañía de Pedro de Valdés representó ante la Reina una comedia titulada La pérdida de España. No es seguro que sea la obra de Lope: Rennert (1907-1908: 46) cree que se trata del título alternativo de La más injusta venganza, comedia atribuida por él mismo a Juan de Velasco y Guzmán. 
Antes de abordar la lista de obras de Nicolás de los Ríos, conviene retomar el caso de El mármol de Felisardo. La comedia figura en el catálogo del Peregrino entre Pedro Carbonero y El favor agradecido, es decir, entre el final de la lista de Granados y el comienzo de la de Vergara. Como ya se ha comentado, la documentación conservada en el Dicat vincula El mármol de Felisardo a los autores Pinedo y Ríos (por una posible representación en 1604) y a Granados (ya que figuró entre las comedias de su repertorio antes de 1606). Pues bien, la fecha de composición que proponen Morley y Bruerton (1594-1598) encajaría con las de las comedias que encabezan la lista de Vergara, puesto que El mármol de Felisardo pasaría a ser de este modo una de las más antiguas de su repertorio:

$$
\begin{aligned}
& \text { El mármol de Felisardo } \\
+ & \text { El favor agradecido } \\
+ & \text { El caballero del milagro } \\
+ & \text { El leal criado } \\
& \text { La reina loca* } \\
+ & \text { El Argel fingido }
\end{aligned}
$$

19 de diciembre de 1593

30 de noviembre de 1593

24 de junio de 1594

Es posible por consiguiente que fuera Vergara el encargado de estrenar El mármol de Felisardo. Se trata no obstante de una hipótesis sin más apoyo documental que la coincidencia entre la fecha propuesta por Morley y Bruerton y su posición en el catálogo, por lo que la apuntamos solamente como una posibilidad.

\section{Nicolás de los Ríos}

Pasemos a continuación a analizar la lista de comedias estrenadas por Nicolás de los Ríos, «mar de donaire y natural gracia». ${ }^{45}$

$$
\begin{aligned}
+ & \text { El verdadero amante } \\
+ & \text { Roncesvalles } * 47 \\
+ & \text { La francesilla } \\
& \text { El rico avariento }{ }^{* 49}
\end{aligned}
$$

$1590-1595^{46}$

Anterior a junio de $1597^{48}$

6 de abril de 1596 (copia Gálvez)

45. El peregrino en su patria, p. 481. No incluyo en esta lista El perseguido, que aparece en el Peregrino entre La bella malmaridada y La poncella de Francia pero que fue estrenada por Cisneros (Wilder 2004: 190). Sobre las comedias de Lope representadas por Ríos, resulta fundamental Reyes Peña (1996).

46. Morley y Bruerton (1968: 262) la adscribieron al periodo 1588-1595, pero Oleza (1986: 303-305) pudo limitar su fecha de composición a los años 1590-1595.

47. En la Biblioteca de Palacio de Madrid se conserva una anónima Comedia de Ronces Valles, «obra fechable en los primeros ańos ochenta del siglo Xvı» (Giuliani 1996: 244) que, como me indica amablemente el propio Giuliani en correspondencia personal, «no tiene nada que ver con Lope».

48. Contamos con un documento en el que consta que el 22 de junio de 1597 Nicolás de los Ríos representó la comedia Roncesvalles en Polán (Toledo). Giuliani (1995: 19-21 y 1997: 1151-1152) transcribe el documento y comenta los problemas críticos que ha suscitado la posible relación de esta pieza con El casamiento en la muerte.

49. Con este mismo título se conserva una comedia de Mira de Amescua y un auto de Rojas Zorri- 


\begin{tabular}{|c|c|}
\hline \multicolumn{2}{|l|}{ La muerte del maestre* } \\
\hline La inclinación natura* ${ }^{*}$ & \\
\hline $\begin{array}{l}\text { El padrino desposado } \\
\text { San Julián de Cuenca*1 }\end{array}$ & $1598 ?-1599^{50}$ \\
\hline $\begin{array}{l}\text { La bella malmaridada } \\
\text { La poncella de Francia* }\end{array}$ & 17 de diciembre de 1596 (copia Gálvez) \\
\hline El caballero de Illescas & Hacia $1602^{52}$ \\
\hline Abindarráez y Narváez ${ }^{53}$ & 16 de octubre de 1596 (copia Gálvez) \\
\hline El marqués de Mantua & 10 de enero de 1596 (copia Gálvez) \\
\hline El ingrato arrepentido & 2 de abril-2 de octubre de 1600 (copia Gálvez) \\
\hline
\end{tabular}

Carecemos de datos acerca de cinco de los catorce títulos que componen esta lista, por lo que resulta difícil extraer conclusiones fehacientes. En cualquier caso, es obvio que las cinco comedias con fecha segura (las copiadas por Ignacio Gálvez) sí guardan cierto orden: Lope escribió cuatro de ellas en 1596 y la última, El ingrato arrepentido, la terminó cuatro años después. Además, la obra que aparece en primera posición, El verdadero amante, es probablemente la más antigua. La fecha propuesta por Cotarelo (1917: Ix) para El caballero de Illescas, confirmada por Morley y Bruerton (1968: 592), no respetaría el orden cronológico, pese a estar situada en un momento muy cercano en el tiempo a la redacción del Peregrino. Otro tanto ocurriría con El padrino desposado, cuyo estreno por parte de Nicolás de los Ríos cuenta con el testimonio de El viaje entretenido, en el que Agustín de Rojas hace decir al personaje de Ríos lo siguiente: «¿No es bueno que nunca pude oílla [una loa], por estarme vistiendo de moro para empezar la comedia del Padrino desposado?». ${ }^{54}$ Se supone que dicha representación tuvo lugar en Granada antes de 1600, por lo que El padrino desposado tuvo que ser compuesta con anterioridad a esa fecha. El terminus a quo, 1598, viene dado por el análisis de la versificación llevado a cabo por Morley y Bruerton y por una referencia a Felipe III, que accedió al trono en septiembre de ese mismo año. Sánchez Aguilar (1998: 1697) advierte no obstante que podría tratarse de un añadido posterior. Por lo demás, el Dicat da cuenta de una escritura, ${ }^{55}$ fechada el 25 de enero de 1601, que registra la venta de 29 manuscritos por parte del au-

lla, además de un auto sacramental de autor desconocido (Urzáiz Tortajada 2002: I, 117 y II, 678). 50. Para la fecha de El padrino desposado, que comentaremos a continuación, véanse los datos que ofrece Sánchez Aguilar (1998: 1696-1697).

51. Según Morley y Bruerton (1968: 421), si la obra titulada El animal profeta, San Julián es de Lope «ha sido refundida».

52. Morley y Bruerton (1968: 81) aceptan la fecha propuesta por Cotarelo (1917: Ix) a raíz de varios recuerdos de Lucinda en la comedia. Por los mismos motivos, Fichter (1924: 270) la había situado entre 1601 y 1603.

53. En la Parte XIII fue impresa con el título El remedio en la desdicha.

54. Agustín de Rojas, El viaje entretenido, p. 186. Llamaron la atención sobre este pasaje Castro y Rennert (1969: 481).

55. El documento completo puede leerse en López Martínez (1940: 69-70). 
tor de comedias Mateo de Salcedo al también director Andrés de Heredia, entre los que figura El padrino desposado. Con todo, no hay por qué dudar de que fuera Nicolás de los Ríos quien efectivamente estrenó El padrino desposado, puesto que entre la nómina de manuscritos se encuentra también La francesilla, que fue estrenada por él mismo. ${ }^{56}$ Ateniéndonos al doble testimonio del estreno de $E l$ padrino desposado por parte de Ríos — su presencia en el repertorio descubierto por Wilder y la alusión presente en El viaje entretenido-, lo más razonable es pensar que Mateo de Salcedo adquirió una copia posterior del autógrafo. Más adelante volveremos sobre esta cuestión.

Contamos con otros datos que nos permiten ampliar el repertorio de Ríos descubierto por Wilder. Tal y como ha señalado Mercedes de los Reyes Peña (1996: 198-199), una escritura fechada en junio de 1589 muestra que la comedia de Lope Los donaires de Matico (citada en dicha escritura con el título La comedia de Matico) formaba parte por aquel entonces del repertorio de Ríos. Antes de que Reyes Peńa diera a conocer este documento, que fija el terminus ad quem de Los donaires de Matico en 1589, Joan Oleza (1986: 301-303) había establecido ya la fecha de composición de la comedia en torno a 1589. Lo más probable, por tanto, es que Lope escribiera Los donaires de Matico para la compañía de Ríos. Veamos ahora el lugar que ocupa en el catálogo del Peregrino:

$$
\begin{aligned}
+ & \text { El Matico }{ }^{57} \\
& \text { Cegries y Bencerrajes }{ }^{* 8} \\
& \text { El tonto del aldea } \\
& \text { La escolástica celosa } \\
& \text { El salteador agraviado }{ }^{* 59} \\
+ & \text { El verdadero amante } \\
+ & \text { Roncesvalles* } \\
+ & \text { La francesilla }
\end{aligned}
$$

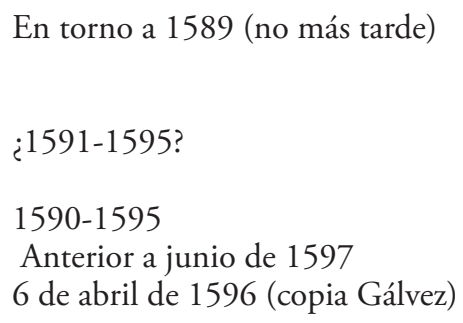

En torno a 1589 (no más tarde)

¿1591-1595?

$1590-1595$

Anterior a junio de 1597

6 de abril de 1596 (copia Gálvez)

El verdadero amante es el primer título que Wilder (1952) incluyó en la lista de obras estrenadas por Nicolás de los Ríos. Así pues, contamos con dos indicios más que corroboran que, en efecto, fue Ríos el encargado de estrenar Los donaires de Matico: a) la escasa distancia a la que se encuentra respecto al repertorio de Ríos; y b) su temprana fecha de composición, que encaja con el orden cronoló-

56. Como recuerda Lope: «Representola el famoso Ríos» (La francesilla, p. 665b).

57. Todos los testimonios de la obra llevan por título Los donaires de Matico, pero debió de circular asimismo con títulos como Matico o Comedia de Matico, pues al final del tercer acto de la princeps puede leerse: "Aquí acaba la Comedia de Matico» (Los donaires de Matico, p. 240).

58. Según Jean Canavaggio, podría tratarse de una versión primitiva de La envidia de la nobleza (Urzáiz Tortajada 2002: I, 133), comedia compuesta probablemente entre 1613 y 1615 (Morley y Bruerton 1968: 322).

59. En la Biblioteca Nacional de Madrid se conserva un auto sacramental con el título El salteador venturoso (Urzáiz Tortajada 2002: I, 120). 
gico de los primeros títulos de la lista de Ríos (El verdadero amante, Roncesvalles y La francesilla). Estos datos, unidos al documento aportado por Reyes Peńa, no dejan lugar a dudas: Lope le vendió el autógrafo de Los donaires de Matico a Nicolás de los Ríos.

Llegados a este punto, cabe preguntarnos si los títulos situados entre Los donaires de Matico y El verdadero amante fueron también estrenados por Ríos. Por desgracia, carecemos de datos acerca de Cegries y Bencerrajes, El tonto del aldea y El salteador agraviado. Detengámonos, pues, en La escolástica celosa, texto que sí se ha conservado. Resulta que una de las obras que figura en la citada escritura del 25 de enero de 1601 - la misma en la que aparecen El padrino desposado y La francesilla, comedias estrenadas por Ríos- lleva por título La escolástica. Podría tratarse de una obra de Liñán de Riaza, citada por Lope en carta al duque de Sessa el 9 de octubre de 1611: «Liñán hizo algunas [comedias], y yo las vi: del Cid eran dos, una de La Cruz de Oviedo y otra que llamaban La escolástica [...]». ${ }^{60}$ Con todo, cabe preguntarse si La escolástica que poseía el autor de comedias Mateo de Salcedo en 1601 no sería en realidad La escolástica celosa, que, curiosamente, aparece citada en el Peregrino dos renglones por encima de El verdadero amante y tres por debajo de Los donaires de Matico, ambas estrenadas por Ríos. De ser así, es probable que el manuscrito de La escolástica tuviera el mismo origen que el de El padrino desposado y La francesilla, todos ellos en poder de Salcedo en 1601: la compañía de Nicolás de los Ríos.

En cuanto a la fecha de composición de La escolástica celosa, Morley y Bruerton (1968: 231) dataron la pieza entre 1596 y 1602, aunque establecieron como fecha más probable el periodo 1599-1602. En cambio, Blecua y Santiáñez-Tió (1997: 1291) advierten que "la datación de la comedia es incierta, aunque lo más probable es que se compusiera con anterioridad a La Arcadia o en fechas muy próximas», y basan su opinión en el hecho de que el soneto «Celos bastardos, malnacidos celos", incluido en La escolástica celosa e impreso asimismo en La Arcadia (publicada en 1598, pero escrita entre 1591 y 1595), parece haber sido compuesto para La escolástica celosa y reaprovechado para La Arcadia, en contra de la opinión de Montesinos:

Hay que recordar, sin embargo, que la comedia se titula, precisamente, La escolástica celosa y que los celos son el eje de la acción dramática. En La Arcadia, en cambio, el soneto está traído por los pelos, para rellenar un pasaje «de camino». Reza el texto: «Con estas y otras muchas razones se despidieron, y consolado Anfriso, volvió al aldea, en cuyo camino, por entretenerle Galafrón, a propósito de los celos cantó así...» e incluye, sin más, el mencionado soneto. Donde encaja, pues, mejor el soneto es en la obra dramática y no en la novela pastoril, aunque allí, como cajón de sastre, todo cabe (Blecua y Santiánez-Tió 1997: 1290). ${ }^{61}$

60. Cita este fragmento Randolph (1984: 130).

61. La presencia de unos versos semejantes en ambas obras lleva a los editores a la misma conclusión. 
Si partimos de la premisa de que fue Ríos quien estrenó La escolástica celosa, la temprana fecha de redacción propuesta por Blecua y Santiánez-Tió (quizás más cerca de 1595 que de 1591, por ajustarla al máximo a la ofrecida por Morley y Bruerton) encaja con el hecho de que La escolástica celosa sería una de las obras más antiguas de la lista de Ríos, con una fecha de redacción cercana a El verdadero amante, y posterior en cualquier caso a Los donaires de Matico, que aparece en primer lugar:

+ El Matico

Cegries y Bencerrajes*

El tonto del aldea*

La escolástica celosa

El salteador agraviado*

+ El verdadero amante
En torno a 1589 (no más tarde)

¿1591-1595?

$1590-1595$

Puede tratarse de una mera coincidencia, pero lo cierto es que son varios los indicios que apuntan en la misma dirección: a) en el catálogo del Peregrino La escolástica celosa figura junto a los títulos que Lope vendió a Ríos; b) una comedia llamada La escolástica aparece citada en un documento en el que se mencionan dos obras de Lope estrenadas por la compañía de Ríos; y c) La probable fecha de composición de La escolástica celosa encaja con su hipotética posición dentro del repertorio de dicho autor de comedias. De este modo, es probable también que el estreno de las obras perdidas situadas entre Los donaires de Matico y El verdadero amante (Cegries y Bencerrajes, El tonto del aldea y El salteador agraviado) corriera a cargo de su compañía.

\section{Gaspar de Porres}

Transcribo a continuación la larga lista de comedias que, según Wilder (1952), Lope vendió a Gaspar de Porres, «autor famoso»:62

+ Las ferias de Madrid

+ Los celos de Rodamonte
Septiembre de $1587^{63}$

$1588^{64}$

62. El peregrino en su patria, p. 481.

63. Sigo a McGrady (2007: 7): «Las ferias de Madrid probablemente data de fines del verano de 1587. El manuscrito apógrafo que suministra el mejor texto de la obra lleva la fecha del 17 de enero de 1589, y existe un acto notarial de 1588 en que el autor de comedias Gaspar de Porres concede autorización a Mateo de Salcedo, otro director teatral, para representar la obra, que ya ha tenido gran éxito, en Granada hasta el 6 de enero de 1589. Parece probable que Lope escribiría Las ferias para representar durante las ferias de Madrid [...], que duraban del 21 de septiembre hasta el 3 de octubre [...]. Como Lope estaba en la Armada Invencible desde mayo hasta fines de octubre en 1588 [...], resulta evidente que el año en cuestión sería 1587, y que la fecha de composición sería hacia septiembre de ese año». 64. La comedia figura en el mismo documento citado en la nota anterior. Tanto Froldi (1968: 140-146) como Maglione (1985: 7-9) aceptan la fecha de 1588. 


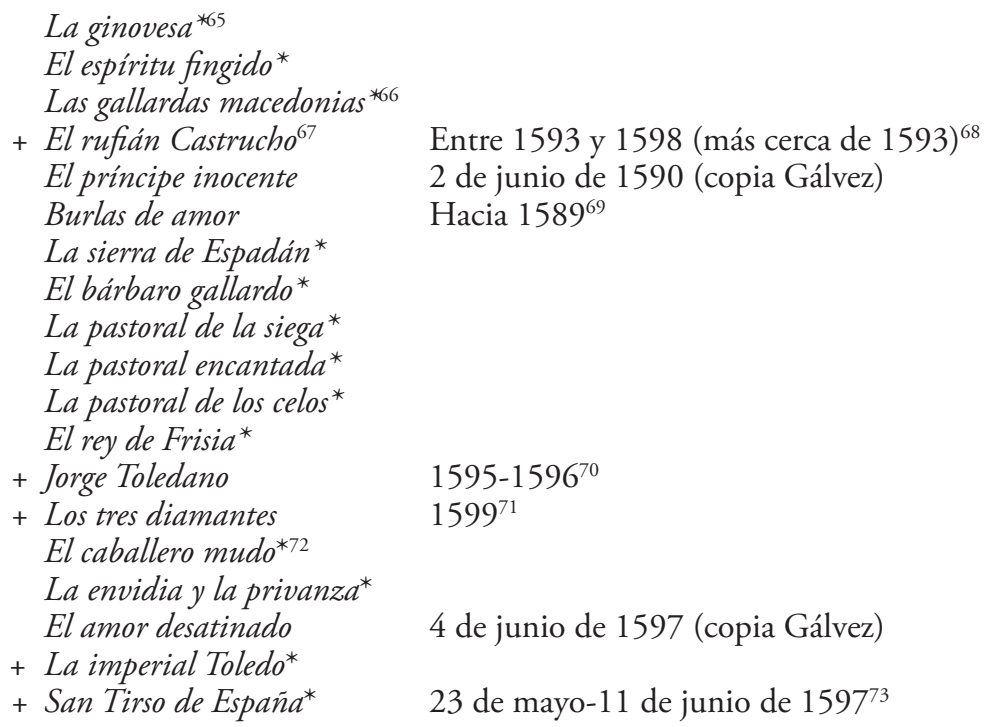

65. La ginovesa, escrita probablemente a finales del siglo XVI, podría tratarse de una versión anterior de La cortesía de España, comedia compuesta seguramente en 1615 (Di Pinto 2013).

66. Cotarelo creyó que podría tratarse de El premio riguroso y la amistad bien pagada, escrita entre 1590 y 1605 pero de autoría dudosa (Morley y Bruerton 1968: 535-536).

67. En la Parte IV figura como El galán Castrucho.

68. Morley y Bruerton (1968: 256) creen que fue escrita hacia 1598, pero Oleza (1986: 305), que constata las muchas semejanzas entre El rufián Castrucho y El caballero del milagro (escrita en 1593 según la copia Gálvez), señala que "habría que localizarla más cerca de 1593 que de 1598». 69. Me baso en los datos que aporta Oleza (1986: 301-303), que precisa la amplia fecha (15871595) de Morley y Bruerton (1968: 238).

70. Tal y como nos informa Lope en la Parte XVII, la comedia fue representada por el autor de comedias Gaspar de Porres, con Agustín Solano en el papel de galán (Case 1975: 182), quien entró en la compañía de Porres en 1595. El terminus ad quem nos lo proporcionan dos documentos que se pueden consultar en el Dicat. Por un lado contamos con una escritura, fechada el 28 de febrero de 1597 , en la que consta que Porres vende el texto de Jorge Toledano a varios representantes. Existe otro documento, fechado asimismo el 28 de febrero de 1597, por el que sabemos que Solano formaba parte ya de la compañía de Nicolás de los Ríos. Por lo tanto, la fecha más probable para Jorge Toledano es 1595-1596. Coincido en este sentido con Wilder (2004: 191), quien señaló que a esas alturas Solano ya no era tan joven, puesto que en el reparto de El tirano castigado de julio de 1599 hizo el papel de viejo rey, por lo que debió de representar el papel de Jorge «con bastante seguridad en 1595 o 1596, y como el papel de Jorge es muy joven, tan temprano como sea posible» (Wilder 2004: 192). Por su parte, Morley y Bruerton (1968: 44) dan como fecha los ańos 1595-1597.

71. Se trata de la fecha que propuso Wilder (2004: 194) a partir de la confluencia de varios datos. Por otro lado, Morley y Bruerton (1968: 50) situaron el terminus ad quem en 1603, pero María Isabel Toro Pascua (1998: 1403), en su edición de la comedia, señala acertadamente que «uno de los sonetos de la obra (vv. 383-396) se imprimió apenas sin cambios entre las Rimas de 1602 con el número 102, por lo que debe ser anterior a la fecha de su aprobación, el 30 de noviembre de ese año».

72. La Barrera cree que puede tratarse de El enamorado mudo, comedia suelta publicada a nombre de Guillén de Castro (Urzáiz Tortajada 2002: II, 656).

73. Para la fecha de San Tirso de España y su vinculación con Porres, véase el reciente artículo de Madrońal (2014). 


$\begin{aligned} & \text { Los Horacios }^{74} \\ & \text { La pobreza estimada } \\ & \text { El triunfo de la limosna } a^{* 77} \\ & \text { El esclavo por su gusto*78 } \\ + & \text { La gran pintora* } \\ & \text { El molino } \\ + & \text { Laura perseguida } \\ + & \text { Los locos de Valencia } \\ & \text { La Circe Angélica*81 } \\ & \text { El cortesano en su aldea }{ }^{* 82} \\ & \text { El Rey Bamba } \\ + & \text { El nuevo mundo } \\ & \text { El mayorazgo dudoso } \\ + & \text { El tirano castigado } \\ + & \text { El amigo por fuerza } \\ + & \text { La fe rompida } \\ + & \text { La Amatilde } \\ + & \text { La hermosura de Alfreda }{ }^{87} \\ + & \text { Los enredos de Celauro } \\ + & \text { La gobernadora* } \\ & \text { Los triunfos de Otaviano* }\end{aligned}$

$1599^{75}$

$1600-1603^{76}$

Antes de febrero de 1597

Antes de marzo de 1594, probablemente 1585-158979

12 de octubre de 1594 (copia Gálvez)

1590-1595 (probablemente más cerca de 1590) ${ }^{80}$

Antes de Cuaresma de $1597^{83}$

$1598-1603^{84}$

$1599^{85}$

17 de julio de 1599 (copia Gálvez)

14 de octubre de 1599 (copia Gálvez)

1599

$1599^{86}$

$1597-1598^{88}$

25 de enero de 1600 (copia Gálvez)

Antes de noviembre de 1591

74. Este título se ha identificado con la comedia El honrado hermano (Morley y Bruerton 1968: 341). 75. La fecha se basa en el estudio de Wilder (2004: 193). Morley y Bruerton (1968: 341) le asignaron como fecha más probable los años 1598-1600.

76. Wilder (2004: 194). Morley y Bruerton (1968: 253) la fechan entre 1597 y 1603.

77. La compañía de Pedro de Valdés representó un auto sacramental con este título en 1621 (DicAT).

78. Se ha relacionado este título con El esclavo fingido, cuya atribución a Lope ha sido fehacientemente rechazada por Arjona (1960: 327-331).

79. Morley y Bruerton (1968: 251) sitúan la fecha de composición entre 1585 y 1595, pero su editora, Patrizia Campana (1997: 1552), aporta varios argumentos que sugieren que la comedia debió de ser escrita probablemente antes de 1589, y casi con total seguridad antes de marzo de 1594 . 80. Para Morley y Bruerton (1968: 249) es de 1590-1595, pero el análisis de Oleza (1986: 303) muestra que parece estar escrita más cerca de la primera fecha.

81. Existe una suelta sin año con el título La Circe de dos coronas (Urzáiz Tortajada 2002: I, 71).

82. Para Restori (Castro y Rennert 1969: 456) podría tratarse de la comedia El cortesano embustero, copia manuscrita que se encuentra en la Biblioteca Palatina de Parma.

83. Wilder (2004: 192). Morley y Bruerton (1968: 223) apuntaban como fecha probable $1597-$ 1598.

84. Sobre la fecha ofrecida por Morley y Bruerton véanse asimismo las observaciones de Giuliani (2002: 179-180). Wilder (2004: 195) baraja la fecha 1597-1599, aunque con algunas dudas.

85. Wilder (2004: 193). Para Morley y Bruerton (1968: 251) es de 1598-1603.

86. Wilder (2004: 194). La fecha más probable para Morley y Bruerton (1968: 241) es 15991603 (este dato se refiere a La resistencia honrada y condesa Matilde, que, como demostraré a continuación, debe de tratarse de la misma obra que La Amatilde).

87. En la Parte IX fue impresa con el nombre La hermosa Alfreda.

88. Wilder (2004: 193). Morley y Bruerton (1968: 226) opinan que la fecha más probable es 1598-1600.

89. En la Parte IV y en la copia Gálvez lleva por título Los embustes de Celauro. 


\section{La conquista del Andalucía*}

+ Los torneos de Aragón 14 de noviembre de 1597 (copia Gálvez)

Como en el caso de Nicolás de los Ríos, carecemos de datos acerca de muchas de las comedias que estrenó Porres. De nuevo el Dicat resulta de gran ayuda para establecer el terminus ad quem de textos que no se han conservado. Consta una escritura, fechada el 28 de febrero de 1597, en la que Gaspar de Porres cede varias comedias, entre ellas tres de Lope: Jorge Toledano, Los locos de Valencia y La pintora. La crítica no ha relacionado este último título con la obra citada como La gran pintora entre las comedias vendidas a Porres. Sin embargo, es muy probable que se trate del mismo texto. Por otro lado, una consulta en DicAT muestra que el 25 de noviembre de 1591 se presentó una censura a propósito de la representación de una comedia titulada La gobernadora por parte del autor «Porres». Roldán Pérez (1991: 72), que fue quien dio a conocer dicha censura, identificó La gobernadora con la obra citada por Lope en el Peregrino. Sin duda, lo más probable es que se trate de la misma comedia, puesto que en ambos casos aparece vinculada a Gaspar de Porres. Este hecho nos permite fijar su terminus ad quem en 1591. La documentación que ofrece el Dicat ratifica por tanto la validez de las conclusiones de Wilder (1952): los datos acerca de la puesta en escena de La gran pintora y La gobernadora por parte de la companía de Porres confirman que fue este autor de comedias quien compró ambos autógrafos. Del mismo modo, la representación de La imperial Toledo el 26 de diciembre de 1604 en Salamanca a cargo de Porres, junto con su aparición en el repertorio de dicho autor de comedias en el Peregrino, dan de nuevo la razón a Wilder (Haley 1971: 262-263).

En cuanto a La Amatilde, creemos, como Wilder (2004: 194), que se trata de la misma obra que se imprimió en la Parte II con el título La resistencia honrada y condesa Matilde, de la que están atestiguadas varias representaciones por parte de la compañía de Porres (Haley 1971: 261). ${ }^{90}$ Otros estudiosos no han relacionado ambos títulos, como Castro y Rennert (1969: 447 y 455), para quienes La resistencia honrada y condesa Matilde es la misma obra que Lope cita en el Peregrino con el título de La condesa, pero no La Amatilde. La misma identificación llevan a cabo Morley y Bruerton (1968: 240) y Urzáiz Tortajada (2002: II, 657), quienes en cambio ni siquiera mencionan La Amatilde. Sin embargo, la documentación conservada acerca de las representaciones por parte de Porres de una comedia titulada La condesa Matilde y el hecho de que La Amatilde figure en el repertorio del Peregrino correspondiente al propio Porres, son motivos de peso para suponer que

90. Como ya apuntó Haley, Wilder debía de desconocer las noticias en torno a su puesta en escena, puesto que incluye la comedia entre el repertorio de Porres pero afirma que no hay pruebas independientes de que fuera él quien la representara (Wilder 2004: 194). En su edición de la pieza, García-Bermejo (1998: 699) afirma asimismo que «tampoco se ha conservado noticia alguna del momento de su representación ni de ante quienes fue llevada a las tablas». 
en realidad son la misma obra. La identificación de La condesa con La resistencia honrada y condesa Matilde no cuenta, en cambio, con más apoyo documental que la semejanza onomástica. ${ }^{91}$ Por otro lado, se ha conservado una comedia suelta, fechada en 1762, con el título de La condesa perseguida y capuchino escocés, atribuida por García de la Huerta a Lope en su catálogo de 1785. No obstante, esta atribución ha sido descartada, entre otros, por Morley y Bruerton (1968: 437). ${ }^{92}$

La lista de Porres es con mucho la más larga, lo que quizás explique que sea la que menos parece obedecer a un criterio cronológico. Con todo, al principio y al final de la lista sí se puede observar cómo Lope tiene en cuenta el momento en que compuso muchas de las piezas. Así, cuatro de las cinco primeras comedias que se han conservado son de fecha muy temprana, escritas entre los años 1587 y 1590 (Las ferias de Madrid, Los celos de Rodamonte, El principe inocente y Burlas de amor). Del mismo modo, hacia el final de la lista se acumulan las obras escritas en torno a los años 1599 y 1600 . Pero también es obvio que el orden no es ni mucho menos estricto, ya que abundan las excepciones. Lope emplea además otros recursos mnemotécnicos que nada tienen que ver con el orden cronológico, como sugiere la secuencia de títulos formada por La pastoral de la siega, La pastoral encantada y La pastoral de los celos. Es posible, por otro lado, que algunas de las obras que aparecen en esta lista no fueran adquiridas por Porres, pues en muchos casos no existe un documento que avale su estreno por parte de dicho autor. Baste recordar el ejemplo de El perseguido, comedia que figura entre las de Ríos cuando en realidad fue Alonso de Cisneros quien la estrenó (Wilder 2004: 190). Ese podría ser el caso de Los locos de Valencia, incluida en la lista de Porres pero que probablemente fue estrenada por Antonio de Villegas, tal y como recordó Lope al publicarla en la Parte XIII..$^{93} \mathrm{Si}$ la he mantenido en esta lista es porque el Dicat arroja documentación fechada entre 1591 y 1592 que muestra cómo por aquellas fechas Villegas fue actor de la compañía de Porres, lo cual plantea alguna duda: «Cuando en 1617 Lope empezó a publicar él mismo sus comedias, a menudo da el nombre del autor a quien se las vendió precedido por la palabra "Representola". En algunos pocos casos, sin embargo, indica el actor o la actriz principales y no el auton (Wilder 2004: 192). Un ejemplo de ello es La viuda valenciana, en la que Lope señala el nombre de la actriz que desempeñó el papel de primera dama, pero no el del autor de la compañía, que no

91. No conviene descartar del todo la posibilidad de que La condesa pueda ser la misma comedia que La Amatilde y que La resistencia honrada y condesa Matilde, en vista de otros casos de obras que aparecen citadas en el Peregrino — de 1618 — con varios títulos, distintos o idénticos (véase la nota 42).

92. La condesa perseguida y capuchino escocés parece ser una pieza tardía, puesto que contiene asonantes entremezclados de siete y once sílabas, "una forma del s. XVIII» (Morley y Bruerton 1968: 437). La obra fue atribuida por La Barrera a fray Félix de Adsaneta, monje capuchino nacido probablemente en 1694 (Herrera Navarro 1993: 3).

93. «Representola Villegas» (Los locos de Valencia, p. 104).

Studia Aurea, 8, 2014 
fue otro que Gaspar de Porres: ${ }^{94}$ "Representola Mariana Vaca, única en la acción y en entender los versos» (La viuda valenciana, p. 99).

Habida cuenta de la fecha propuesta por Oleza para Los locos de Valencia (1590-1595, más cerca de 1590), es posible que Villegas fuera el actor y no el autor de comedias. Además, el Dicat da cuenta de una escritura del 28 de febrero de 1597 en la que Porres cedía varios textos dramáticos, entre ellos Los locos de Valencia, lo cual podría ser un indicio más de que fue él quien la estrenó.

Una búsqueda en Dicat permite ampliar la lista de comedias vendidas a Gaspar de Porres. Según se lee en el Diario de un estudiante de Salamanca, ${ }^{95}$ el 24 de julio de 1606 se representó en Salamanca una comedia titulada La gitana hermosa, con total seguridad a cargo de Porres. En el Dicat se sugiere que La gitana hermosa podría ser la comedia citada en el Peregrino con el título La bella gitana. ${ }^{96}$ En vista de los datos acerca de su puesta en escena, la similitud onomástica y su cercanía respecto a las comedias estrenadas por Porres (tres renglones por debajo), parece indudable que se trata de la misma obra:

+ Los torneos de Aragón El desdichado*

La mudable*

+ La bella gitana*

Los torneos de Aragón es el último de los títulos que Wilder (1952) incluyó en la lista de Porres, pero lo más probable es que estrenara también La bella gitana y, por ende, El desdichado y La mudable, todas ellas perdidas.

Entre el final de la lista de Nicolás de los Ríos y el inicio de la de Gaspar de Porres solo figuran tres títulos: El sufrimiento premiado, Ursón y Valentín y Segunda de Ursón. El sufrimiento premiado se imprimió en el Segundo tomo de las comedias de Juan Pérez de Montalbán (Madrid, 1638), pero Victor Dixon demostró que no pudo ser obra suya, sino que, muy probablemente, se trata de la comedia citada por el Fénix en el Peregrino. ${ }^{97}$ A raíz de diversos indicios, Dixon (1967: xxvi) estableció el año de 1603 como su fecha de redacción más probable. En cuanto a Ursón y Valentín, que apareció publicada en la Parte I de Lope (Madrid, 1604), Joan Oleza (1986: 301-303) pudo situar su fecha de composición en torno al año 1589. Nada sabemos, en cambio, de la obra titulada Segunda de Ursón.

En vista de estos datos, creo que es posible aventurar la hipótesis de que $E l$ sufrimiento premiado fue estrenada por Nicolás de los Ríos, mientras que Ursón y

94. Tal y como señala Ferrer Valls (2001: 99).

95. Girolamo Da Sommaia, Diario de un estudiante de Salamanca, p. 233.

96. Haley (1971: 266), que confesaba no haber podido consultar la edición original del Peregrino, se había planteado ya esta cuestión: "¿Será La bella gitana, ahora perdida, que Lope menciona en $\mathrm{P}$ [eregrino]?».

97. Véase Dixon (1961: 105-109 y 1967: VII-XXVII). 
Valentín (y, probablemente, Segunda de Ursón) fue escrita para Gaspar de Porres. Carecemos de documentación que vincule estas comedias con puestas en escena por parte de Ríos o Porres, pero las fechas de composición ofrecidas por los estudiosos, así como el lugar que ocupan en el catálogo del Peregrino, me parecen datos suficientes como para tener en cuenta esta posibilidad. Véamoslo detenidamente:

\begin{tabular}{|c|c|}
\hline \multirow{5}{*}{$\begin{aligned} & \text { El marqués de Mantua } \\
+ & \text { El ingrato arrepentido } \\
& \text { El sufrimiento premiado } \\
& \text { Ursón y Valentín } \\
& \text { Segunda de Ursón } \\
+ & \text { Las ferias de Madrid } \\
+ & \text { Los celos de Rodamonte }\end{aligned}$} & $10 \mathrm{de}$ \\
\hline & (copia Gálv \\
\hline & \\
\hline & En torno a 1589 \\
\hline & 1587 \\
\hline
\end{tabular}

El ingrato arrepentido y Las ferias de Madrid son, respectivamente, la última comedia de la lista de Ríos y la primera de la de Porres. Teniendo en cuenta la tendencia de Lope de situar las obras más antiguas al principio de cada una de estas listas, y las más antiguas al final, se observa que las fechas de redacción de El sufrimiento premiado y de Ursón y Valentín encajarían con la posición que ocuparían en los repertorios de Ríos y Porres: El sufrimiento premiado pasaría a ser la comedia más reciente escrita para Ríos y Ursón y Valentín una de las más viejas de Porres, con una fecha de composición cercana a Las ferias de Madrid (1587), Los celos de Rodamonte (1587-1588), El principe inocente (1590) o Burlas de amor (1589), que figuran en las primeras posiciones de su repertorio. Como digo, no contamos con más datos que vinculen El sufrimiento premiado y Ursón y Valentín con estos autores, pero, en vista de los indicios señalados, me parece una hipótesis probable que fueran ellos quienes las llevaran por primera vez a las tablas.

\section{Baltasar de Pinedo}

Reproduzco a continuación la lista de obras adquiridas por Baltasar de Pinedo, «maravilloso entre los que en España han tenido este título»: $:^{98}$

+ La serrana de la Vera

$1595-1598 / 1599$

+ La fuerza lastimosa

$1599^{99}$

98. El peregrino en su patria, p. 481.

99. Para la datación de La fuerza lastimosa, La Galiana, La batalla naval y Las pobrezas de Reinaldos adopto las fechas ofrecidas por Wilder (1953) a partir del estudio de diversos aspectos de la compañía de Pinedo (la presencia de niños en el reparto, el uso de un león o de un disfraz de león en escena, el papel de Juana de Villalba, etc.). Wilder precisa algunas de las fechas ofrecidas por Morley y Bruerton: 1595-1603 (La fuerza lastimosa), 1597-1602 (La Galiana) y 1598-1600 (La batalla naval). La fecha de Las pobrezas de Reinaldos coincide con la de Morley y Bruerton. Por su parte, García Lorenzo (1972) sugiere que en La fuerza lastimosa Lope parece conocer la comedia 

+ La Galiana ${ }^{100}$
La Basilea*
+ La batalla naval 101
+ Los Benavides
+ La venganza de Gaiferos*
+ La ocasión perdida
+ Las pobrezas de Reinaldos
La dama desagraviada*
La prisión de Muza*
+ El catalán valeroso ${ }^{102}$

1599

1599

15 de junio de 1600 (autógrafo fechado)

$1599-1603$

1599

1600 / 1599-1603 (más cerca de esta última fecha) ${ }^{103}$

Antes de adentrarnos en los problemas de datación de La serrana de la Vera, baste recordar que Wilder (1953: 22), a raíz del estudio de las características de la compañía de Pinedo, advirtió que La serrana de la Vera fue "probably the first play Lope wrote for the new company». De este modo, ya fuera escrita entre 1595 y 1598 (Morley y Bruerton) o en 1599 (Wilder), la comedia que aparece en primer lugar es de nuevo la más antigua de la lista. Tras La serrana de la Vera figuran varias piezas compuestas en 1599, una en 1600 (Los Benavides) y otra entre 1599 y 1603 (La ocasión perdida). En último lugar se sitúa El catalán valeroso, que es probablemente la más tardía. Resulta complicado calibrar la exactitud de Lope - contamos con datos muy imprecisos y todas las comedias que se han podido fechar con seguridad fueron escritas entre 1599 y 1600 - , pero parece que en cierto modo tiene presente el momento en el que compuso varias de sus obras: las más antiguas están colocadas al principio de la lista, mientras que algunas de las más tardías se sitúan al final. En cualquier caso, sería natural que Lope no respetara a rajatabla el orden de unas comedias que fueron escritas con tan solo un año de diferencia: como hemos tenido ocasión de observar a lo largo de estas páginas, la cronología que sigue el Fénix es siempre aproximada.

No hay consenso entre la crítica en torno a la fecha de composición de $L a$ serrana de la Vera. Morley y Bruerton (1968: 223-224) propusieron como terminus ad quem septiembre de 1598, habida cuenta de que aparece citada en El galán

El conde Alarcos de Guillén de Castro (Alberola 1998: 77), compuesta probablemente entre 1600 y 1602, pero los datos analizados por Wilder (1953) no permiten suponer una fecha tan tardía para la comedia de Lope.

100. Con este título aparece en el Peregrino. En la Parte XXIII se la cita como Los palacios de Galiana.

101. En la Parte $X V$ figura con el título de La Santa Liga.

102. Así en el Peregrino. En la Parte II aparece como El gallardo catalán.

103. Morley y Bruerton (1968: 50) la consideran escrita entre 1599 y 1603 , probablemente en 1600. En su edición de la comedia, Enrique Turpin (1998: 400-406) argumenta que lo más probable es que fuera escrita en una fecha cercana a 1603, sobre todo debido al predominio de sonetos de tipo A (con tercetos CDCDCD), ya que El gallardo catalán es, junto a Los tres diamantes, la comedia más antigua con esta peculiaridad. Nótese, sin embargo, que Wilder (2004: 194) fechó Los tres diamantes en 1599. 
escarmentado, ${ }^{104}$ obra que juzgan anterior a la muerte de Felipe II, ocurrida el 13 de septiembre de 1598. El galán escarmentado contiene una alusión que, según notaron Cotarelo y Montesinos, implicaría que Felipe II aún estaba vivo: «Mira este parque y palacio / de Filipo sin segundo». ${ }^{105}$ Wilder (1953: 22) rechaza los argumentos de Morley y Bruerton, puesto que a su juicio El galán escarmentado no tiene por qué haber sido compuesta con anterioridad a la muerte del monarca:

This antedating is unnecessary. Philip III and his court do not seem to have been offended by hearing the king's father referred to as «Filipo sin segundo»; the expression even more strongly phrased occurs in a play which we know to have been finished by Lope on February 15, 1600 — La contienda de García [...]: «El príncipe Filipo, aunque segundo, / para ser sin segundo vino al mundo» (Wilder 1953: 22-23).

El ejemplo que aporta Wilder no deja lugar a dudas de que Lope no tenía ningún miramiento en referirse a Felipe II con expresiones de este tipo, incluso cuando el monarca ya había fallecido. Montesinos (1924: 304) defiende no obstante que en El galán escarmentado se «alude a Felipe II como aún vivo». Deberemos, por tanto, centrarnos en el contexto; en el pasaje en cuestión, Lope describe los jardines y la Casa Palacio de la Casa de Campo: ${ }^{106}$

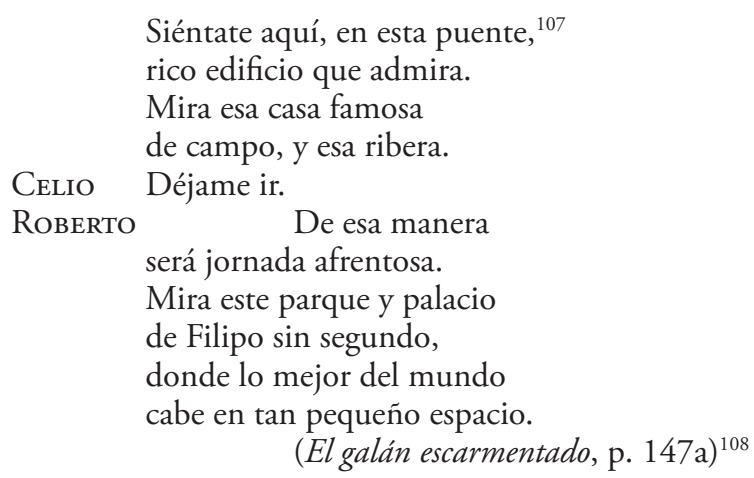

Cotarelo, Montesinos y Morley y Bruerton entienden que «Filipo sin segundo» no puede ser otro que Felipe II, y que la alusión implica que el monarca aún estaba vivo. ${ }^{109}$ Sin embargo, no creo que eso deba ser forzosamente así. La

104. Con el título La serrana de Plasencia.

105. El galán escarmentado, p. 147a.

106. La Casa de Campo era un lugar de recreo muy querido por los madrileńos, formado por un conjunto de jardines amurallados en torno a un palacete (Navascués 1991 y Fernández 2003). Lope describe sus edificios, fuentes y flores en varias comedias, como La noche de San Juan (vv. 1286-1325), La gallarda toledana (vv. 843-918) y en diversos pasajes de Lo que pasa en una tarde. 107. Se refiere al puente de Segovia, por el que se accedía a la Casa de Campo.

108. La puntuación del pasaje es mía.

109. Más recientemente, Navarro Durán (1996: 213) ha repetido la misma suposición. 
creación de la Casa de Campo se debe, es cierto, a Felipe II, bajo cuyo mandato se empezó a construir en 1562. En La gallarda toledana, escrita probablemente en 1603, Lope la describe en los siguientes términos:

Llego a Madrid, y a la entrada

a ver los jardines entro, obra insigne del Segundo

para Felipe Tercero.

(La gallarda toledana, vv. 1503-1506)

Es decir, que pasados cinco años de la muerte de Felipe II, Lope todavía hace hincapié en que fue el Rey Prudente quien llevó a cabo la construcción de la Casa de Campo. No me parece tan inverosímil, pues, que uno o dos años después —en torno a 1599 o 1600, por ajustar la fecha al máximo a la ofrecida por Morley y Bruerton- Lope pudiera referirse a la Casa de Campo como el «parque y palacio / de Filipo sin segundo", por mucho que su nuevo inquilino fuera Felipe III.

En cualquier caso, suponer una fecha anterior a 1599 implica no pocos problemas. Las primeras noticias conservadas acerca de Pinedo como autor de comedias datan de 1601, fecha que se ha podido adelantar a 1599 en vista de que estrenó varias obras de Lope compuestas ese mismo año. En los años noventa trabajó como actor en diversas compañías, y solo un documento, fechado en 1596, se refiere a Pinedo como «autor de comedias». Lola González (2008: 1395), que defiende la fecha propuesta por Morley y Bruerton para La serrana de la Vera, argumenta que «si la comedia fue escrita por Lope para que la representara Pinedo bien podría haber estado ya redactada en 1596, año en el que existe una primera referencia documental a Pinedo como autor de comedias", y sugiere que los dos episodios de la obra en los que aparece un león —uno de los aspectos en los que Wilder apoya su datación- pudieron deberse a un retoque posterior del manuscrito original o de una de sus copias. Ahora bien, conviene tener presente la observación de Enrico Di Pastena (2008: 26-27):

En marzo de 1596 [Baltasar de Pinedo] firmó en Madrid una obligación, referente al pago por su alojamiento de los últimos meses, donde aparece mencionado como «autor de comedias»: o su proyecto de compañía propia no cuajó o duró muy poco. Lo cierto es que el documento de 1596 es de uso privado y se remonta a la Cuaresma (época del año en que la actividad dramática estaba de hecho paralizada). [...] De confirmarse las fechas de redacción [1595-1598] o no descubrirse documentos que adelanten el estreno de Pinedo como director, habría que suponer que éste acabe quedándose piezas que en origen Lope había escrito para otros directores, cuando aquéllas ya habían perdido parte de su novedad; pero no hay que olvidar que Wilder [1953-1954] retrasó a después de 1598 la fecha de La serrana.

Todos los indicios apuntan no obstante a que fue Baltasar de Pinedo y no otro autor quien estrenó La serrana de la Vera: la comedia figura en la lista de obras estrenadas por su compañía en el catálogo del Peregrino, así como en una escritura, 
fechada el 31 de marzo de 1616, por la que Pinedo vendía a Francisco de Ávila doce comedias, todas ellas compradas a Lope, entre las cuales figuraba La serrana de la Vera (Di Pastena 2008: 9-15 y DiCAT). Además, la primera representación de la que se tiene noticia, que tuvo lugar el 26 de abril de 1604 en Salamanca, corrió a cargo de su compañía (DicAT). En cualquier caso, La serrana de la Vera es anterior al resto de obras vendidas a Pinedo, que es el dato que nos importa retener aquí.

En cuanto a las comedias que se han perdido, el Dicat proporciona una vez más datos de sumo interés. Sabemos que el 23 de abril de 1604 se estrenó en Salamanca una comedia titulada El conde Galvano o el nacimiento de Gaifebo [sic] irlandés - que debió de titularse en realidad El conde Galvano o el nacimiento de Gaiferos irlandés - obra que a buen seguro fue llevada a las tablas por Pinedo, ya que por esas fechas su compañía se encontraba representando en la capital salmantina (DiCAT). Esta comedia se inspira en el ciclo de Gaiferos, que narra las siguientes peripecias:

El ciclo de Gaiferos tiene como trasfondo varias narraciones folclóricas, pero se sitúa en un ambiente pseudocarolingio: el conde don Galván es asesinado por su propio hermano, que se casa con la viuda y manda matar al hijo de Galván, Gaiferos. El niño es abandonado en el bosque y criado por un tío suyo, que le enseña el arte de la caballería, y años después regresa a la casa materna para vengar la muerte de su padre. Asentado ya en la corte del emperador, se casa con Melisendra, hija de Carlomagno; ésta es cautivada por los moros y Gaiferos emprende la hazaña de rescatar a su esposa, cautiva en Sansueña, con ayuda de Roldán, quien le presta sus armas y su caballo (Díaz Mas 2008: 248-249).

Es indudable, pues, que El conde Galvano o el nacimiento de Gaiferos irlandés, representada en 1604 por Baltasar de Pinedo, es la misma comedia que La venganza de Gaiferos, situada entre las de su repertorio en el catálogo del Peregrino. Este hecho confirma de nuevo la validez de la hipótesis de Wilder, que ya supuso que La venganza de Gaiferos fue escrita para este autor de comedias, hipótesis que avala la documentación conservada.

Respecto a La dama desagraviada, otra de las comedias perdidas, el Dicat muestra que el 14 de octubre de 1604 se representó en Salamanca una obra titulada Lucinda desagraviada. La posible identificación entre ambos títulos se refuerza por el hecho de que por aquel entonces la compañía de Baltasar de Pinedo todavía estaba afincada en Salamanca, donde llevó a cabo varias funciones (Dicat). En el Dicat se sugiere que podría tratarse de la obra de Lope Lucinda perseguida, pero esta comedia fue estrenada por Melchor de León, ${ }^{110}$ por lo que es mucho más probable que se aluda a La dama desagraviada. Con todo, en esas fechas también estaba representando la compañía de Nicolás de

110. Lucinda perseguida, p. 324. 
los Ríos (DicAT), por lo que no podemos asegurar a ciencia cierta que Lucinda desagraviada sea la misma obra que La dama desagraviada. Se trata no obstante de una hipótesis probable, en vista de la semejanza onomástica y de que $L a$ dama desagraviada figura entre las obras estrenadas por Pinedo.

El Dicat permite además ampliar considerablemente el repertorio de Pinedo presente en el Peregrino. Según se lee en el Diario de un estudiante de Salamanca (p. 160), el 22 de abril de 1604 — esto es, un día antes que El conde Galvano o el nacimiento de Gaiferos irlandés - se representó en Salamanca La divina vencedora, citada en el Peregrino dos renglones por encima de La serrana de la Vera, título que encabeza la lista de Pinedo descubierta por Wilder. Tres renglones por encima de La divina vencedora se encuentra Los Jacintos: se trata de La pastoral de Jacinto, publicada por primera vez en el volumen Cuatro comedias de diversos autores (Córdoba, 1613) como la Comedia de los Jacintos y celoso de sí mismo. ${ }^{11}$ Esta obra se representó en Salamanca, con el título El celoso de sí mismo, el 3 de mayo de 1604, apenas diez días después que La divina vencedora y El conde Galvano o el nacimiento de Gaiferos irlandés (DiCAT). ${ }^{112}$ Tal y como se sugiere en el Dicat, lo más probable es que el autor de comedias encargado de la puesta en escena de La divina vencedora y El celoso de sí mismo fuera el propio Baltasar de Pinedo, puesto que, como venimos viendo, por esas fechas están documentadas varias representaciones por parte de su compañía. Esta posibilidad se confirma por el lugar que ocupan las piezas en la lista del Peregrino:

\begin{tabular}{|c|c|}
\hline Los Jacintos & $1588-1595^{113}$ \\
\hline $\begin{array}{l}\text { La campana de Aragón } \\
\text { La reina de Lesbos* }\end{array}$ & 1596-1603, probablemente $1598-1600$ \\
\hline $\begin{array}{l}+ \text { La divina vencedora } \\
\text { Los jueces de Ferrara }\end{array}$ & $1599-1603$ \\
\hline La serrana de la Vera & $1595-1598 / 1599$ \\
\hline La fuerza lastimosa & 1599 \\
\hline + La Galiana & 1599 \\
\hline
\end{tabular}

Como se puede apreciar, Los Jacintos y La campana de Aragón ocuparían las primeras posiciones de la lista de Pinedo. En el caso de Los Jacintos su estreno por parte de Pinedo se confirma por la temprana fecha de redacción, que la convierte en la obra más antigua de la lista: de ahí que aparezca en primer lugar.

111. La patoral de Jacinto es el título con el que fue impresa en la Parte XVIII. Véase la edición de Paola Ambrosi (1997: 1-10).

112. Este hecho confirma la suposición de Ambrosi (1997: 10), que vio en el título de la edición de 1612 «un richiamo accattivante per il pubblico nell'edizione di Cordova, che si può pensare legata ad una messa in scena». En efecto, la comedia debió de circular como El celoso de sí mismo, a juzgar por el título con el que figura en la representación de 1604 y por los versos finales de la edición de 1612: «dando fin a la comedia / del celoso de sí mismo» (La pastoral de Jacinto, p. 189). 113. Las fechas se deben a Ambrosi (1997: 19-24). 
La posición que ocupan La campana de Aragón y La divina vencedora invita asimismo a pensar en fechas de composición cercanas en ambos casos a los termini a quo ofrecidos por Morley y Bruerton.

Retomando la cuestión del año en que Baltasar de Pinedo inició su andadura como autor de comedias, la fecha de redacción de Los Jacintos - y, en menor medida, de La campana de Aragón - puede ser un indicio de que, en efecto, en torno al año 1596 Pinedo estuvo al frente de su propia compañía. Sin duda, futuras investigaciones podrán arrojar nueva luz sobre este asunto.

Por último, el Diario de un estudiante de Salamanca (p. 179) —obra en la que figuran los últimos datos, recogidos en el Dicat, que venimos comentando- da fe de la representación, el 30 de abril de 1604, de una comedia titulada La presa de Álora y Baza. Según se explica en el DicaT, son varios los datos que nos permiten asegurar a ciencia cierta que la puesta en escena corrió a cargo de Pinedo: por un lado, constan varias representaciones suyas en Salamanca durante esos meses; por otro, Andrés de Claramonte, cuya presencia en la compañía de Pinedo está atestiguada por otros testimonios, fue el encargado de glosar dos pies. Por mi parte, creo que resulta indudable que La presa de Álora y Baza es la misma obra que Lope cita en el Peregrino como La toma de Álora. La puesta en escena a cargo de Pinedo y, sobre todo, el lugar que ocupa en el catálogo del Peregrino - justo después de El catalán valeroso, la última de las comedias que Wilder incluyó entre las de su repertorio-, son pruebas suficientes para afirmar que Pinedo fue el encargado de estrenar La toma de Álora, que probablemente fue compuesta entre 1600 y 1603 . Es probable asimismo que tanto La villanesca como El monstro de amor, obras que no se han conservado y que figuran a continuación de La toma de Álora, fueran adquiridas por Pinedo. Con ellas se cierra la lista de comedias de El peregrino en su patria.

Entre La bella gitana y Los Jacintos - es decir, entre el final de la lista de Porres y el comienzo de la de Pinedo- figura La firmeza de Leonarda, texto perdido del que no se ha conservado noticia alguna. Resulta imposible determinar qué compañía fue la encargada de llevarla a las tablas por vez primera, aunque probablemente fuera o bien la de Porres o bien la de Pinedo.

\section{Melchor de Villalba}

Fijémonos a continuación en cuatro comedias que Lope vendió a Melchor de Villalba, las cuales conforman una pequeña lista que conviene añadir a las descubiertas por Wilder (1952):

+ El maestro de danzar

$1594^{114}$

114. Según se señala en el colofón del apógrafo conservado: «Hice esta comedia en Alba / para Melchor de Villalba, / y porque es verdad, firmelo / el mes que es mayor el hielo / y el año que Dios nos salva. / 1594». Esta fecha se ha venido interpretando como enero de 1594 (Fernández Rodríguez 2012: 15). 
+ El dómine Lucas

+ Los Chaves de Villalba ${ }^{116}$

+ Los muertos vivos 1591-mayo de $1593^{115}$

20 de agosto de $1599^{117}$

1599-1602

Es indudable que Lope vuelve a guiarse por un criterio cronológico. En el momento de escribir el catálogo del Peregrino, comedias como El dómine Lucas y El maestro de danzar tienen ya diez años de antigüedad, por lo que no resultaría nada extraño que Lope, aunque hubiera querido seguir un orden cronológico preciso, no recordara o no tuviera manera de saber exactamente cuál escribió primero. En cambio, es absolutamente consciente de que piezas como Los Chaves de Villalba y Los muertos vivos son mucho más recientes. De hecho, es muy probable que Los muertos vivos, la última de la lista de Villalba, sea la más cercana en el tiempo al Peregrino.

En vista de los datos reunidos — a la fuerza incompletos-, podemos afirmar que el orden cronológico, de un modo más o menos estricto, rige los repertorios del Peregrino, sobre todo en lo que respecta a situar las obras más antiguas al principio de los mismos y las más recientes, al final. Solamente la lista de comedias estrenadas por Gaspar de Porres, la más larga de todas, presenta una apariencia más caótica, aunque se respetan ciertas pautas. En conclusión, la cronología constituye para Lope una ayuda más que un fin. Es natural: del mismo modo que los repertorios de las compañías, el orden en que fue componiendo sus obras le podía servir como recurso mnemotécnico a la hora de confeccionar el catálogo del Peregrino, lo cual no quiere decir que siempre y sin excepciones quisiera o pudiera respetar este criterio. A fin de cuentas, tampoco en la redacción de los repertorios se muestra Lope muy estricto, puesto que hay varios ejemplos de títulos que aparecen en el catálogo pero no dentro de la lista que les correspondería. Este es el caso, por ejemplo, de El primer rey de Castilla (Vergara), El sol parado (Ríos) o El perseguido (Cisneros).

115. Fue Guillermo Carrascón (1997: 40) quien pudo precisar las fechas de 1591-1595 ofrecidas por Morley y Bruerton (1968: 44). En la primera escena de la comedia, situada en Alba de Tormes, se alude a la muerte del «viejo Duque» (Fadrique II Álvarez de Toledo) y a la ausencia de su «sucesor», su sobrino Antonio Álvarez de Toledo, quinto duque de Alba. La ausencia del duque se corresponde con total seguridad con el periodo (1591-1593) en que don Antonio estuvo encarcelado en el Castillo de la Mota a causa de su matrimonio, contraído sin permiso real, con dońa Mencía de Mendoza. Por otro lado, el 13 de mayo de 1593 se celebraron unas fiestas de toros en las que, en un desgraciado accidente, perdió la vida don Diego de Toledo, hermano bastardo de don Antonio. Como señala Carrascón, no parece razonable que Lope escribiera una obra como El dómine Lucas (en cuya primera escena se alude largamente a una fiesta de toros) tras el infortunio sucedido, por lo que cabe pensar que la comedia es anterior a ese fatídico 13 de mayo de 1593 .

116. En la Parte X se imprimió como El blasón de los Chaves de Villalba. La noticia del estreno por parte de Villalba se debe a Wilder (2004: 192).

117. Se trata de la fecha transmitida en el apógrafo de Sanz de Pliegos (Rodríguez Rodríguez 2010: 1189). 
En este punto es obligado remitirse a las reflexiones de Luigi Giuliani en torno a la ordenación de las comedias del Peregrino:

Como es sabido, Lope fue agrupando los títulos de la lista de 1604 siguiendo el repertorio de los autores para los que habían sido compuestas las comedias. Tal vez para Lope se trataba en su momento de un recurso cómodo, de orden mnemotécnico (y quizás pudo echar mano de listas manuscritas en que pudo anotar los encargos recibidos de cada compañía), un patrón preferible a otros posibles criterios de ordenación, como el meramente cronológico, por géneros u otros. Sin embargo, creo que el criterio elegido, que se basa en el fondo en la estrecha vinculación del texto dramático con las circunstancias de su representación (en este caso, con las compañías que lo pusieron en escena), puede darnos un indicio más de que a estas alturas la autonomía del texto teatral como objeto literario susceptible de lectura no estaba todavía clara para Lope, y que el cordón umbilical que unía el texto y el espectáculo era aún muy fuerte (Giuliani 2004: 136).

Considero que Giuliani lleva toda la razón cuando señala que el criterio elegido por Lope tiene que ver con las particularidades de la difusión y la transmisión del fenómeno teatral en la época. Pero, como sugiere el propio Giuliani, a Lope le resultaría asimismo muy útil disponer de una ayuda para poder recordar el máximo número de títulos. Al fin y al cabo, la intención principal del Fénix con la publicación del catálogo del Peregrino era la de "definire il proprio corpus» (Profeti 1998: 21) frente al volumen de Crasbeeck aparecido en 1603: acudir a los repertorios de las compañías a las que había vendido sus obras, así como disponer las distintas listas partiendo de un orden cronológico, le facilitaría enormemente tan ardua labor. Por ahí, me parece de sumo interés el apunte de Giuliani acerca de las posibles listas manuscritas que Lope pudo ir confeccionando con los encargos recibidos por parte de las distintas compañías teatrales. Si se confirmara esta hipótesis - muy verosímil - el orden cronológico de los repertorios del Peregrino - a veces aproximado, en ocasiones bastante preciso- sería una consecuencia natural del método empleado por el Fénix, pues reflejaría, de modo más o menos riguroso, el orden en que Lope fue anotando los sucesivos encargos. Orden que, a su vez, y en vista de casos como El primer rey de Castilla, El sol parado o El perseguido, presentaría no pocas salvedades y algún que otro olvido.

Expongo a continuación un esquema de los 219 títulos que conforman el catálogo del Peregrino, con el número de piezas que contiene cada uno de los repertorios. En el cómputo global de obras estrenadas por cada autor de comedias el lector debe tener en cuenta la ampliación de los repertorios que se ha defendido a lo largo del artículo:

73 comedias (?)

4 comedias (Melchor de Villalba)

20 comedias (?)

7 comedias (Antonio Granados) 
El mármol de Felisardo (?)

14 comedias (Luis de Vergara)

9 comedias $^{118}($ ?)

21 comedias (Nicolás de los Ríos + El perseguido por Alonso de Cisneros) ${ }^{119}$

49 comedias (Gaspar de Porres) ${ }^{120}$

La firmeza de Leonarda (texto perdido. ¿Porres, Pinedo?)

18 comedias (Baltasar de Pinedo) ${ }^{121}$

Los datos de que disponemos en la actualidad invitan a pensar que en un primer momento Lope no echa mano de los repertorios de las compañías. La lista del Peregrino está conformada por 219 títulos, pero parece que Lope escribe los 97 primeros (es decir, cerca de la mitad) sin recurrir a ellos, a excepción solamente de las cuatro comedias vendidas a Villalba. En cambio, una vez anota las comedias estrenadas por Granados, serán excepcionales los casos en que no siga este criterio, al margen de que algunas de nuestras hipótesis puedan ser erróneas. Si asumimos que la disposición final de los títulos refleja el orden en que Lope los fue anotando una vez decidió emprender la redacción del catálogo, es verosímil suponer que en un principio el Fénix recurriera principalmente a su memoria, pero que pronto se diera cuenta de la necesidad de valerse de otros recursos, tales como los repertorios de las compañías y el orden cronológico, para lo cual las posibles listas de encargos a las que aludía Giuliani le resultarían de gran ayuda. Con todo, investigaciones futuras podrían arrojar nuevos datos acerca de repertorios que hoy por hoy desconocemos, por lo que estas conclusiones no dejan de ser provisionales.

118. Las nueve comedias son: San Andrés carmelita, Nerón cruel, El primero Médicis, El capitán Juan de Urbina, San Segundo de Ávila, El cerco de Madrid, La torre de Hércules, Los Guzmanes de Toral y El conde de Irlos. Solamente existen datos seguros acerca del estreno de Los Guzmanes de Toral, que fue llevada a las tablas por el autor de comedias Pedro Llorente (DiCAT).

119. Se incluye en el recuento El sufrimiento premiado, situada en último lugar, antes de Ursón $y$ Valentín.

120. En el recuento se contabilizan las comedias Ursón y Valentín y Segunda de Ursón.

121. Incluyo las dos piezas que cierran el catálogo, La villanesca y El monstro de amor, ambas perdidas. 


\section{Bibliografía}

Alberola, Montgrony (ed.), Lope de Vega, La fuerza lastimosa, en Comedias de Lope de Vega. Parte II, coord. S. Iriso, Lérida, Milenio-Universitat Autònoma de Barcelona, 1998, I, 69-243.

Ambrosi, Paola (ed.), Lope de Vega, La pastoral de Jacinto, Kassel, Reichenberger, 1997.

Arata, Stefano, «Teatro y coleccionismo teatral a finales del siglo XVI (el conde de Gondomar y Lope de Vega)", en Textos, géneros, temas: investigaciones sobre el teatro del Siglo de Oro y su pervivencia, eds. S. Arata, F. Antonucci, L. Arata, M. del Valle Ojeda, Pisa, ETS, 2002, 141-157.

Arjona, J. H., «Ten Plays Attributed to Lope de Vega», Hispanic Review, 28 (1960), 319-340.

Blecua, Alberto, y Nil Santiáñez-Tió (eds.), Lope de Vega, La escolástica celosa, en Comedias de Lope de Vega. Parte I, Lérida, Milenio-Universitat Autònoma de Barcelona, 1997, III, 1285-1396.

Campana, Patrizia (ed.), Lope de Vega, El molino, en Comedias de Lope de Vega. Parte I, Lérida, Milenio-Universitat Autònoma de Barcelona, 1997, III, 1547-1686.

Carrascón, Guillermo, «Nunca segundas partes fueron buenas: Lope, del Dómine Lucas al Maestro de danzar», Anuario Lope de Vega, 3 (1997), 37-50.

Case, Thomas E., Las dedicatorias de partes XIII-XX de Lope de Vega, Madrid, Castalia, 1975.

Castro, Américo, y Hugo A. Rennert, Vida de Lope de Vega, Salamanca, Anaya, 1969.

Cornejo, Manuel, «La esclava de su galán (¿1626?): nuevos datos acerca de las estancias sevillanas de Lope de Vega", Anuario Lope de Vega, 9 (2003), 195210.

Cornejo, Manuel (ed.), Lope de Vega, El Arenal de Sevilla, en Comedias de Lope de Vega. Parte XI, coords. L. Fernández y G. Pontón, Madrid, Gredos, 2012, II, 459-610.

Cotarelo y Mori, Emilio (ed.), Obras de Lope de Vega publicadas por la Real Academia Española (Nueva edición), Madrid, Tipografía de la «Revista de archivos», IV, 1917.

—, Obras de Lope de Vega publicadas por la Real Academia Española (Nueva edición), Madrid, Tipografía de la «Revista de archivos», VII, 1930.

Da Sommaia, Girolamo, Diario de un estudiante de Salamanca. La crónica inédita de Girolamo da Sommaia (1603-1607), ed. G. Haley, Salamanca, Universidad de Salamanca, 1977.

Di Pastena, Enrico, «La Séptima parte, historia editorial», en Comedias de Lope de Vega. Parte VII, coord. E. Di Pastena, Lérida, Milenio-Universitat Autònoma de Barcelona, 2008, I, 9-65.

Di Pinto, Elena, «Versiones y reescrituras: laboratorio de hacer comedias», en 
Teatro español de los Siglos de Oro. Dramaturgos, textos, escenarios, fiestas, dir. J. M. Díez Borque, Madrid, Visor Libros, 2013, 99-116.

Díaz Mas, Paloma, "El romancero caballeresco», en Amadis de Gaula, 1508: quinientos años de libros de caballerías, Madrid, Biblioteca Nacional de España-Sociedad Estatal de Conmemoraciones Culturales, 2008, 245-250.

Díez Borque, José María, Sociedad y teatro en la España de Lope de Vega, Barcelona, Antoni Bosch, 1978.

Dixon, Victor, «Juan Pérez de Montalbán’s Segundo tomo de las comedias», Hispanic Review, 29 (1961), 91-109.

Dixon, Victor (ed.), Lope de Vega, El sufrimiento premiado, Londres, Tamesis Books Limited, 1967.

Fernández, José Luis, Bahamonde, Ángel, Barreiro, Paloma, y Jacobo Ruiz del Castillo, La Casa de Campo. Más de un millón de años de historia, Madrid, Lunwerg-Ayuntamiento de Madrid, 2003.

Fernández Rodríguez, Daniel (ed.), El maestro de danzar, en Lope de Vega, El maestro de danzar. La creación del mundo, Madrid, Gredos, 2012, 11-258.

Ferrer Valls, Teresa (ed.), Lope de Vega, La viuda valenciana, Madrid, Castalia, 2001.

Ferrer Valls, Teresa (dir.), Diccionario biográfico de actores del teatro clásico español (DICAT) [Recurso electrónico], Kassel, Reichenberger, 2008. Consulta del 15 de enero de 2014.

Fichter, William L., «Notes on the Chronology of Lope de Vega's Comedias», Modern Language Notes, vol. 39, no 5 (1924), 268-275.

Froldi, Rinaldo, Lope de Vega y la formación de la comedia, Madrid, Anaya, 1968.

García-Bermejo Giner, Miguel M. (ed.), La resistencia honrada y condesa Matilde, en Comedias de Lope de Vega. Parte II, coord. S. Iriso, Lérida, MilenioUniversitat Autònoma de Barcelona, 1998, II, 697-837.

García López, Jorge (ed.), Lope de Vega, El primer Fajardo, en Comedias de Lope de Vega. Parte VII, coord. E. Di Pastena, Lérida, Milenio-Universitat Autònoma de Barcelona, 2008, II, 967-1087.

-, El postrer godo de España, en Comedias de Lope de Vega. Parte VIII, coord. R. Ramos, Lérida, Milenio-Universitat Autònoma de Barcelona, 2009, II, 723-870.

García Lorenzo, Luciano, El tema del Conde Alarcos del Romancero a Jacinto Grau, Madrid, CSIC, 1972.

García Reidy, Alejandro, «Notas a un problema de repertorios teatrales (Lope de Vega, Pinedo y el difunto Vergara)", en En Teoría hablamos de Literatura. Actas del III Congreso Internacional de Aleph, coords. A. C. Morón Espinosa y J. M. Ruiz Martínez, Granada, Dauro-Universidad de Granada, 2007, 462-468.

-, Las musas rameras. Oficio dramático y conciencia profesional en Lope de Vega, Madrid, TC/12-Iberoamericana-Vervuert, 2013.

Giuliani, Luigi, «En el taller del dramaturgo: uso de las fuentes y de los recursos es- 
cénicos en El casamiento en la muerte», Anuario Lope de Vega, 1 (1995), 19-35.

-, "Un indicio del éxito del teatro de Juan de la Cueva», Anuario de Estudios Filológicos, 19 (1996), 241-248.

—, «El prólogo, el catálogo y sus lectores: una perspectiva de las listas de El peregrino en su patria», en Lope en 1604, coord. X. Tubau, Lleida, Universitat Autònoma de Barcelona-Prolope-Milenio-Sociedad Estatal de Conmemoraciones Culturales, 2004, 123-136.

Giuliani, Luigi (ed.), Lope de Vega, El casamiento en la muerte, en Comedias de Lope de Vega. Parte I, Lérida, Milenio-Universitat Autònoma de Barcelona, 1997, II, 1149-1276.

—, Lope de Vega, El nuevo mundo descubierto por Cristóbal Colón, en Comedias de Lope de Vega. Parte IV, coords. L Giuliani y R. Valdés, Lérida, MilenioUniversitat Autònoma de Barcelona, 2002, I, 175-287.

González, Lola (ed.), Lope de Vega, La serrana de la Vera, en Comedias de Lope de Vega. Parte VII, coord. E. Di Pastena, Lérida, Milenio-Universitat Autònoma de Barcelona, 2008, III, 1391-1519.

Granja, Agustín de la (ed.), Lope de Vega, El bosque de amor. El labrador de la Mancha, Madrid, CSIC, 2000.

Haley, George, «Lope de Vega y el repertorio de Gaspar de Porras en 1604 y 1606», en Homenaje a William L. Fichter, eds. A. D. Kossoff y J. A. Vázquez, Madrid, Castalia, 1971, 257-268.

Herrera Navarro, Jerónimo, Catálogo de autores teatrales del siglo XVIII, Alcalá, Fundación Universitaria Española, 1993.

Herzog, Werner (ed.), Luis Vélez de Guevara, Comedia famosa del rey don Sebastián, Madrid, Real Academia Española, 1972.

Iglesias Feijoo, Luis, «La única edición de las Seis comedias de Lope de Vega (Lisboa, 1603)», en Golden-Age Essays in Honour of Don W. Cruickshank, eds. M. Cunningham, G. Magnier y A. Ward, Bulletin of Spanish Studies, 90 (2013), 719-734.

IrIso ArIz, Silvia, "Estudio de la colección Gálvez: fiabilidad y sentido de los apógrafos de Lope de Vega», Anuario Lope de Vega, 3 (1997), 99-143.

José Prades, Juana de, y Alicia López, «En torno a una compilación de documentos sobre Lope de Vega», en Otro Lope no ha de haber, a cura di M. G. Profeti, Firenze, Alinea, 2000, 133-142.

López Martínez, Celestino, Teatros y comediantes sevillanos del siglo XVI, Sevilla, Imprenta Provincial, 1940.

Madroñal, Abraham, "San Tirso de Toledo, tragedia perdida de Lope de Vega», Hipogrifo, 2, 1 (2014), 23-54.

Maglione, Sabatino G. (ed.), Lope de Vega, Los celos de Rodamonte, LanhamNew York-London, University Press of America, 1985.

McGrady, Donald (ed.), Lope de Vega, Las ferias de Madrid, Newark, Juan de la Cuesta, 2007.

MenÉndez Pelayo, Marcelino, «Observaciones preliminares», en Obras de Lope 
de Vega publicadas por la Real Academia Española, Madrid, Sucesores de Rivadeneyra, 1898, VIII, ix-cxlvii.

Menéndez Pelayo, Marcelino (ed.), Obras de Lope de Vega publicadas por la Real Academia Española, Madrid, Sucesores de Rivadeneyra, 1901, XII.

Montesinos, José F., "Contribución al estudio de la lírica de Lope de Vega», Revista de Filología Española, 11 (1924), 298-311.

Morley, S. Griswold, y Courtney Bruerton, Cronología de las comedias de Lope de Vega, Madrid, Gredos, 1968.

Navarro Durán, Rosa, «Sonetos de El galán escarmentado en un manuscrito», Anuario Lope de Vega, 2 (1996), 213-220.

Navascués, Pedro, Ariza, María del Carmen, y Beatriz Tejero, «La Casa del Campo", en A propósito de la Agricultura de Jardines de Gregorio de los Ríos, eds. J. Fernández Pérez e I. González Tascón, Madrid, Real Jardín Botánico-CSICÁrea de Medio Ambiente del Ayuntamiento de Madrid, 1991, 137-159.

Olezz, Joan, «La propuesta teatral del primer Lope de Vega», en Teatro y prácticas escénicas, II. La comedia, ed. J. Oleza, Londres, Tamesis Books, 1986, 251308.

Pontón, Gonzalo (ed.), Lope de Vega, El bautismo del príncipe de Marruecos, en Comedias. Parte XI. coords. L. Fernández y G. Pontón, Madrid, Gredos, II, 2012, 791-960.

Presotto, Marco, «Hacia la producción del texto-espectáculo en las comedias autógrafas de Lope», Anuario Lope de Vega, 3 (1997), 153-168.

—, Le commedie autografe di Lope de Vega: catalogo e studio, Kassel, Reichenberger, 2000.

Profeti, Maria Grazia, Nell'officina di Lope, Firenze, Alinea, 1998.

Ramos, Rafael, "La Octava parte: historia editorial», en Comedias de Lope de Vega. Parte VIII, coord. R. Ramos, Lérida, Milenio-Universitat Autònoma de Barcelona, 2009, I, 9-55.

Ramos, Rafael (ed.), Lope de Vega, La prisión sin culpa, en Comedias de Lope de Vega. Parte VIII, coord. R. Ramos, Lérida, Milenio-Universitat Autònoma de Barcelona, 2009, II, 871-984.

Randolph, Julian F., «Obras mal atribuidas a Liñán de Riaza», Anuario de Letras, 22 (1984), 111-134.

Rennert, Hugo A., "Notes on the Chronology of the Spanish Drama", Modern Language Review, 2 (1906-1907), 331-341.

-, "Notes on the Chronology of the Spanish Drama. II.», Modern Language Review, 3 (1907-1908), 43-55.

Reyes Peña, Mercedes de los, "Una nota sobre el terminus ad quem de Los donaires de Matico, de Lope de Vega, y su inclusión en el repertorio de Nicolás de los Ríos», Anuario Lope de Vega, 2 (1996), 197-211.

—, "Vida y martirio de Santa Bárbara, una comedia inédita de la colección teatral del conde de Gondomar», Criticón, 87-89 (2003), 745-764.

Rodríguez Rodríguez, José Javier (ed.), Lope de Vega, El blasón de Los Chaves de 
Villalba, en Comedias de Lope de Vega. Parte X, coords. R. Valdés y M. Morrás, Lérida, Milenio-Universitat Autònoma de Barcelona, 2010, III, 1187-1361. Rojas, Agustín de, El viaje entretenido, ed. J. Joset, Madrid, Espasa-Calpe, I, 1977. Roldán PÉrez, Antonio, «Polémica sobre la licitud del teatro: actitud del Santo Oficio y su manipulación», Revista de la Inquisición, 1 (1991), 63-103.

SAn Román, Lope de Vega, los cómicos toledanos y el poeta Sastre: serie de documentos inéditos de los años de 1590 a 1615, Madrid, Imprenta Góngora, 1935.

San Vicente, Ángel, «El teatro en Zaragoza en tiempos de Lope de Vega», en Homenaje a Francisco Ynduráin, ed. A. Beltrán, Zaragoza, Universidad de Zaragoza, 1972, 267-361.

Sánchez Aguilar, Agustín (ed.), Lope de Vega, El padrino desposado, en Comedias de Lope de Vega. Parte II, coord. S. Iriso, Lérida, Milenio-Universitat Autònoma de Barcelona, 1998, III, 1693-1822.

Sánchez Jiménez, Antonio, El Sansón de Extremadura: Diego García de Paredes en la literatura española del siglo XVI, Newark, Juan de la Cuesta, 2006.

Toro Pascua, María Isabel (ed.), Lope de Vega, Los tres diamantes, en Comedias de Lope de Vega. Parte II, coord. S. Iriso, Lérida, Milenio-Universitat Autònoma de Barcelona, 1998, III, 1401-1558.

Tubau, Xavier (coord.), Lope en 1604, Lleida, Universitat Autònoma de Barcelona-Prolope-Editorial Milenio, 2004.

Turpin, Enrique (ed.), Lope de Vega, El gallardo catalán, en Comedias de Lope de Vega. Parte II, coord. S. Iriso, Lérida, Milenio-Universitat Autònoma de Barcelona, 1998, I, 397-548.

Urzáiz Tortajada, Héctor, Catálogo de autores teatrales del siglo XVII, Alcalá, Fundación Universitaria Española, 2002.

Vega Carpio, Lope de, El desposorio encubierto, ed. E. Cotarelo y Mori, en Obras de Lope de Vega publicadas por la Real Academia Española (Nueva edición), Madrid, Tipografía de la «Revista de archivos», 1917, IV, 507-542.

-, Los donaires de Matico, ed. M. Presotto, en Comedias de Lope de Vega. Parte I, Lérida, Milenio-Universitat Autònoma de Barcelona, 1997, I, 115-254.

-, Los esclavos libres, ed. E. Cotarelo y Mori, en Obras de Lope de Vega publicadas por la Real Academia Española (Nueva edición), Madrid, Tipografía de la «Revista de archivos», 1918, V, 397-439.

-, La francesilla, ed. E. Cotarelo y Mori, en Obras de Lope de Vega publicadas por la Real Academia Española (Nueva edición), Madrid, Tipografía de la «Revista de archivos», 1918, V, 665-700.

-, El galán escarmentado, ed. E. Cotarelo y Mori, en Obras de Lope de Vega publicadas por la Real Academia Española (Nueva edición), Madrid, Tipografía de la «Revista de archivos», 1916, I, 117-152.

-, La gallarda toledana, ed. D. Fernández, en Comedias. Parte XIV, coord. J. E. López Martínez, Madrid, Gredos, en prensa.

-, Lo que pasa en una tarde, ed. R. A. Picerno, Valencia, Chapel Hill, The University of North Carolina Press, 1971. 
—, Los locos de Valencia, ed. H. Tropé, Madrid, Castalia, 2003.

—, Lucinda perseguida, ed. E. Cotarelo y Mori, en Obras de Lope de Vega publicadas por la Real Academia Española (Nueva edición), Madrid, Tipografía de la «Revista de archivos», 1930, VII, 324-361.

—, La noche de san Juan, ed. A. K. Stoll, Kassel, Reichenberger, 1988.

—, La pastoral de Jacinto, ed. P. Ambrosi, Kassel, Reichenberger, 1997.

—, El peregrino en su patria, ed. J. B. Avalle-Arce, Madrid, Castalia, 1973.

—, El postrer godo de España, ed. J. García López, en Comedias de Lope de Vega. Parte VIII, coord. R. Ramos, Lérida, Milenio-Universitat Autònoma de Barcelona, 2009, II, 723-870.

—, La viuda valenciana, ed. T. Ferrer Valls, Madrid, Castalia, 2001.

Wilder, Thornton, «New Aids Toward Dating the Early Plays of Lope de Vega», en Varia variorum. Festgabe für Karl Reinhardt, Münster-Colonia, Böhlau Verlag, 1952, 194-200.

—, "Lope, Pinedo, Some Child-Actors, and a Lion», Romance Philology, 7 (1953), 19-25.

—, «Nuevos instrumentos para fechar las comedias tempranas de Lope de Vega», en Lope en 1604, coord. X. Tubau, Lleida, Prolope-UAB-Milenio, 2004, 189-196. 